\title{
Overview of Sensitivity Analysis Methods Capabilities for Traction AC Machines in Electrified Vehicles
}

\author{
Pedram Asef ${ }^{1}$, Senior Member, IEEE, and Andrew Lapthorn² ${ }^{2}$ Senior Member, IEEE \\ ${ }^{1}$ University of Hertfordshire, Department of Engineering and Technology, Hatfield, AL10 9AB United Kingdom \\ ${ }^{2}$ University of Canterbury, Department of Electrical and Computer Engineering, Christchurch, New Zealand \\ Corresponding author: Pedram Asef (e-mail: p.asef@herts.ac.uk).
}

\begin{abstract}
A robust design in electrified powertrains substantially helps to enhance the vehicle's overall efficiency. Robustness analyses come with complexity and computational costs at the vehicle level. The use of sensitivity analysis (SA) methods in the design phase has gained popularity in recent years to improve the performance of road vehicles while optimizing the resources, reducing the costs, and shortening the development time. Designers have started to utilize the SA methods to explore: i) how the component and vehicle level design options affect the main outputs i.e. energy efficiency and energy consumption; ii) observing sub-dependent parameters, which might be influenced by the variation of the targeted controllable (i.e. magnet thickness) and uncontrollable (i.e. magnet temperature) variables, in nonlinear dynamic systems; and iii) evaluating the interactions, of both dependent, and sub-dependent controllable/uncontrollable variables, under transient conditions. Hence the aim of this study is to succinctly review recent utilization of SA methods in the design of AC electric machines (EM)s used in vehicle powertrains, to evaluate and discuss the findings presented in recent research papers while summarizing the current state of knowledge. By systematically reviewing the literature on applied SAs in electrified powertrains, we offer a bibliometric analysis of the trends of application-oriented SA studies in the last and next decades. Finally, a numericalbased case study on a third-generation TOYOTA Prius EM will be given, to verify the SA-related findings of this paper, alongside future works recommendations.
\end{abstract}

INDEX TERMS Automotive engineering, AC machines, electric vehicles, robustness, sensitivity analysis, permanent magnet machines, time series analysis, statistics.

\section{INTRODUCTION}

М ANAGING the environmental and energy 1 requirements of road transport by vehicle electrification is a challenging task, because of the cost, computational time, and the complex nature of the powertrains. The identified complexities are a result from technical immaturity as electrified vehicles have not yet penetrated the market on a broad scale. Sensitivity analysis (SA) in existing literature and textbooks, as applied in the automotive industry, illustrates that the use of various SA methods have been widely performed. Depending on the type of study and mathematical skills of the designers, the level of contribution and methodology selection vary; factor prioritization [1-6], factor fixing [6-10], variance cutting [56][11], and factor mapping [6] [12-13] are employed in engineering applications such as automotive. Fully electric and hybrid electric vehicles (EV/HEV)s designers particularly should:

a. Distinguish the behavior of the objectives in HEV/EV powertrains. For instance, the nonlinear nature of the torque trend in electric motors can only be traced if the higher order differential equations are computed. The question to be examined is "Does the linearity or nonlinearity of the objective need to be determined?"

b. Evaluate the measurement error of various SA methods leading to a higher level of confidence in the powertrain. The question to be examined is "What level of uncertainty exists in each methodology?"

c. Recognize which design variable footprints in the powertrain are noisy. In other words, the powertrain input variables, such as battery capacity, mass, inverter and electric motors ratings, can be subjected to uncertainty in the output. The question to be examined 
is "Where are the origins of these uncertainties and how do they affect the powertrain objectives?"

The reason that we stated the above-mentioned questions is defining how uncertainty analysis (case b) and SA (case c) are different from each other. Although, the SA evaluates how uncertainty in the component level of the powertrain (inputs) influences the powertrain objectives (outputs). The majority of published SAs in the field of electrified vehicles are either local [14-34] (such as one-factor-at-a-time (OAT) [24-34]) analyses, based on unjustified assumptions of model linearity and additivity. In fact, most of the HEV/EV powertrain models are nonlinear which raises the following question, "What would be the consequences if the SA results are incorrect?" On the other hand, global sensitivity analyses (GSA) [35-45], which avoids the aforementioned shortcomings, are only employed by a minority of designers. From the literature published on SA-focused studies for different HEV [46-48] and EV [50-52] powertrain topologies in both commercial [51-53] and passenger [54-55] vehicles, a remarkable lack of the availability of data can be seen. Due to the broad and multidisciplinary engineering involved in transportation electrification, the need of up-to-date application-oriented research and validation is obvious. All the SA-related attempts on HEV/EV powertrains can be summarized in the main component level outputs as: (1) electric motors and generators [56-58]; (2) batteries [59-66]; (3) longitudinal dynamics (physical sizing) [67-73]; and (4) energy management units [74-76].

The electrified powertrains for most of the transportation design variables on the above-mentioned components performance are discussed. Knowing the importance of corresponding design variables mentioned in (1-4) will offer new insights into how the energy consumption and powertrain, instant changes of speed due to driving behavior, speeding, and braking changes over time. These changes can be evaluated under different standardized drive cycles, where application-oriented drive cycles are presented. Due to these conditions, the importance of demand torque and speed have increased scrutiny. In reality, performance of the vehicle is always assumed to operate under the pre-defined drive cycles which are measured for various real-case driving. Therefore, the torque-speed-efficiency profile and transient temperature of the electric motors employed will be nonlinear and non-monotonical. In particular, an increase of temperature in PMSMS can suppress the torque density of the motor significantly. The component level SA helps designers to optimize the electric motors performances in a wide-speed-range. However, this does not allow them to evaluate the performance of the motor under real case driving cycles, where more nonlinearities occur due to the dynamic nature of the application, as presented Figure 1, where instances of acceleration and deceleration can happen in seconds. Ignoring facts like temperature rise of the motors may result in safety issues. Note that driving torque (DT) and regenerative torque (RT) are acceleration and deceleration modes in Figure 1.

Table I presents the worldwide trend of applied sensitivity analysis methods in automotive engineering (AE) within last decade. The total number of AE-related literature published is $1,041,940$, however, the total number of AE-related works that have employed SA methods is only 284 . On the other hand, the total number of SA-focused articles is 23,496, while only 1,626 , meaning that about $6.92 \%$ papers were reporting the use of GSA methods. Among all AE-related publications, a very low AE contribution of less than $1 \%$ used SA methods in their design process. This trend shows that higher research and development requirements need to be defined for a faster and more efficient design and optimization. Although, the above statistics are for buses, and commercial vehicles (e.g. trucks), they are subjected to including all types of SA methodologies such as: (1) onefactor-at-a-time (OAT); (2) DOE-based LSA; (3) regressionbased LSA; and (4) GSA, but we believe that the choice of method with respect to the component characteristics is sometimes mistakenly ignored which results in either an inefficient design or faulty prediction. For example, assume that the OAT method was used for the design variables selection of an energy storage system (e.g. size of battery, capacity, temperature, etc.) of the vehicle, afterwards, the predicted power consumption (output) mismatches the experimental measurements. If the SA implementation and modelling have been done correctly, the most likely reason might be the SA methodology employed. Moreover, the use of GSA methods in AE is only in 64 articles in the last decade, less than $4 \%$ of total papers published applying GSA methods. While a large portion of their use can be reported from 2018-2020, by 41 publications. This fact highlights the importance of these methodologies to provide reliable results for nonlinear and dynamic components and systems such as e-motors.

The next section emphasizes which SA methods are appropriate to be used for highly engineering a design depending on the component characteristics. Another

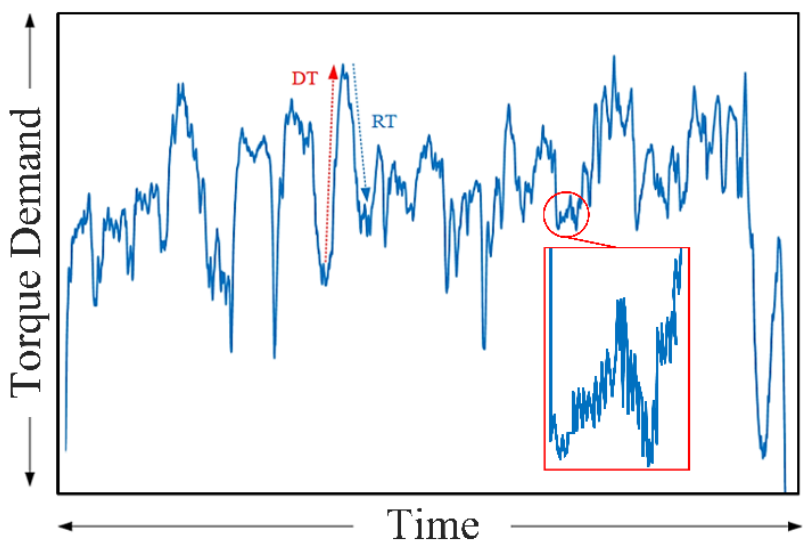

FIGURE 1. Component and system level torque variation for a fully electric vehicle under TRL M25 drive cycle. 
TABLE I.

The Number of ARticles Which have ApPlied SA Methods in AE Within the LAST DeCAdE

\begin{tabular}{|c|c|c|c|c|c|c|c|c|c|c|c|c|c|}
\hline \multirow{2}{*}{ Method } & \multicolumn{9}{|c|}{ Number of articles [year-to-yearl } & Total \\
\cline { 2 - 12 } & $\mathbf{0 9 / 1 0}$ & $\mathbf{1 0 / 1 1}$ & $\mathbf{1 1 / 1 2}$ & $\mathbf{1 2 / 1 3}$ & $\mathbf{1 3 / 1 4}$ & $\mathbf{1 4 / 1 5}$ & $\mathbf{1 5 / 1 6}$ & $\mathbf{1 6 / 1 7}$ & $\mathbf{1 7 / 1 8}$ & $\mathbf{1 8} / \mathbf{1 9}$ & $\mathbf{1 9 / 2 0}$ & \\
\hline $\begin{array}{c}\text { OAT applied } \\
\text { in AE }\end{array}$ & 9 & 11 & 12 & 3 & 6 & 2 & 13 & 7 & 9 & 19 & 22 & 113 \\
\hline $\begin{array}{c}\text { DOE/R applied } \\
\text { in AE }\end{array}$ & 3 & 4 & 2 & 5 & 4 & 8 & 5 & 6 & 15 & 24 & 31 & 107 \\
\hline $\begin{array}{c}\text { GSA applied in } \\
\text { AE }\end{array}$ & 2 & 1 & 1 & 3 & 2 & 2 & 2 & 3 & 7 & 17 & 24 & 64 \\
\hline $\begin{array}{c}\text { Total articles } \\
\text { on AE }\end{array}$ & 55,454 & 58,477 & 65,721 & 73,031 & 80,725 & 92,867 & 106,299 & 118,038 & 122,458 & 132,201 & 136,669 & $1,041,940$ \\
\hline $\begin{array}{c}\text { Total articles } \\
\text { on GSA }\end{array}$ & 42 & 48 & 86 & 108 & 130 & 154 & 172 & 200 & 208 & 231 & 247 & 1,626 \\
\hline $\begin{array}{c}\text { Total articles } \\
\text { on SA }\end{array}$ & 1,369 & 1,488 & 1,646 & 1,842 & 2,036 & 2,200 & 2,347 & 2,591 & 2,513 & 2,676 & 2,788 & 23,496 \\
\hline
\end{tabular}

* Note that the numbers provided in Table I are own calculations from peer-reviewed journal articles and international conferences,

reported in web of science, google scholar, and SJR.

inference verified by Table 1 is that there still is dominance of OAT-LSA in AE-related literature, by 113 (approximately double of GSA).

While the variation of many EMs' parameters, under dynamic operations, is nonlinear. The main highlights of the work are to demonstrate how conventional SA methods such as OAT and DOE/R may result in failure in such a dynamic system like EVs/ HEVs. Less recognized, but increasingly significant, are uses of these existing SA methods on three critical parameters such as torque, power loss, and temperature. The aim of this overview is to present and evaluate the state-of-the-art of the available reports on the applied SA methods of the electric motors in the EVs/ HEVs. After this introductory section, the characteristics of each one of those motor topologies will be summarized in Section II, in which a comprehensive comparative discussion over those candidates are given. SA methods used by the researchers will be discussed based on proposed mappings. Section III reviews the most common types of SA methods and proposes some of the methods based on the Section II highlights. Section IV offers a numerical-based study on a Third-Generation TOYOTA Prius to verify the necessity behind using GSAs. Finally, the main highlights and significant findings of the article are listed in Section IV, where future visions and recommendations are given.

\section{ELECTRIC MOTORS IN ELECTRIFIED POWERTRAINS: STATE-OF-THE-ART}

This section reviews the latest findings on the component level of HEV/EV powertrains, in addition, we will propose a mapping of the linearity or nonlinearity behavior of main outputs, to examine whether the SA methods applied are suitable or not for that specific component in the literature.

- Electrical Machines (EM)s

The available recent types of EMs used in electrified vehicles are given as follows:

\section{a. Permanent Magnet Synchronous Motors (PMSM)s}

\section{b. Switched Reluctance Motors (SRM)s \\ c. Induction Motors (IM)s}

\section{a. Permanent Magnet Synchronous Motors (PMSM)s}

In the traction market, PMSMs have been widely used recently. Due to some remarkable advantages of this type of motor, such as wide torque-speed-range with high efficiency, and high torque and power densities, they are still highly under research and development. The following topologies have been developed during recent years:

- Interior PMSMs (IPMSM)s

- Surface-Mounted PMSMs (SPMSM)s

- Double Stator/Rotor PMSMs (DSRPMSM)s

- Flux Switching PMSMs (FSPMSM)s

Researchers in [77-88] have proposed IPMSMs for $\mathrm{HEV} / \mathrm{EV}$ s because of many advantages such as lower risk of magnet demagnetization and higher reliability. L. Zhang et $a l$, [77] have studied three-phase and five-phase IPMSMs. Due to low reliability under the faulty conditions of conventional IPMSMs topologies such as spoke-type and Vshape (for example in the Toyota-Pirus 2004[78-79]), they have proposed two new fault tolerant fractional-slot concentrated-winding IPMSMs which have offered a high fault-tolerant capacity in comparison to other designs reported in [87-88]. In another study [80], the authors have developed a new spoke-type IPMSM with higher electromagnetic capability in both low and high speed operations toward the Toyota-Piros motor [78-79].

S. Zhu et al. have studied IPMSMs in EV applications [81-82] and [86], in reference [81] they have studied electromagnetic performance of three multi-layered rotors. Finally, they have prototyped an IPMSM with a rotor consisting of three-layered magnets due to better torque density, and improved eddy-current loss and harmonics of the airgap flux density. In another study [82], they have reduced the stator core loss. Due to the harmonics of the rotor magnetomotive force, the stator core loss has been decreased by increasing the rotor magnet layers. In [86], they have 
compared the different rotor structures to calculate the iron loss and efficiency of multi-layered IPMSMs.

Y. H. Hwang and J. Lee [85] have presented the future of heavy rare-earth free magnets in IPMSMs. They have reported that the losses of the heavy rare-earth free magnets are less than $\mathrm{Nd}$ sintered magnets within high speed operation. Additionally, the efficiency of the proposed injection type motor with heavy rare-earth magnets is higher than typical Nd magnet IPMSM.

Recent literature on SPMSMs in HEV/EV applications are reported in [89-93]. Y. P. Yang and M. T. Peng [89] have illustrated a SPMSM with a magnet surface of a sinusoidal pulse width modulation (SPWM) shape by four factors: the period and modulation ratios of the SPWM function, the magnet tooth height, and the magnet base thickness, which were also verified via sensitivity analysis. They have found on the optimal shape of the magnets, in which the maximum torque has approximately decreased only up to $5.4 \%$. While the magnet volume has reduced up to $13.2 \%$ which significantly decreased the cost of motor. In another investigation [90], the researchers have presented the electromagnetic and thermal characteristics of an overhang structure in a SPMSM. They have proposed an analytical method, the lumped-parameter thermal network, to minimize the computation time in comparison with the computational fluid dynamics method. It should be mentioned that the overhang structure is suitable where high torque and power densities in a limited space is preferable such as in $\mathrm{HEV} / \mathrm{EV}$.

N. P. Shah et al. [91], have investigated a high pole, axial-flux SPMSM with a variable stator alignment of independent stators, thus allowing field weakening via a controllable and variable generated-voltage constant. There are several advantages of this type of topology:

- A wide constant-power speed ratio

- Better performance within high-speed operation

- Elimination of all gear ratio changes of the vehicle

- Downsizing of the motor drive

- Lower total cost

- Higher efficiency

- Extending the gradeability/ acceleration range of the vehicle without the use of gear changes

J. Fan et al. [92], have studied a lumped parameter thermal analysis of a PMSM by considering a real driving cycle. Because of critical irreversible demagnetization and insulation failure of coils under severe thermal condition in PMSMs, they have computed heat losses and predicted temperature distribution of the motor under a real driving duty cycle. Finally, the lumped parameter model is verified by a core loss calculation method which is based on finite element analysis (FEA). In another report [93], the designers have worked on an exterior-rotor, radial-flux wheel motor that directly drives the vehicle. With respect to its structural/electromagnetic design difficulties, the performance improvement of the motor has been affected. They have enhanced the SPMSM in:

- No-load flux density and electromagnetic force

- Torque performance

- Stator current and temperature rise have been reduced at a certain level

- Flux leakage reduction

A better post-processing design or optimisation often results in a more complex motor. Researchers have developed new topologies to improve the conventional motors. In recent years, novel DSR-PMSM topologies have been reported for electrified vehicle applications [94-102]. In [94], the authors have investigated a flux-modulated doublerotor machine for series-parallel HEVs. In another work [95], they have proposed a novel double stator flux modulation machine with low-temperature superconducting windings. Higher torque density, stronger flux weakening capability, and larger power factor have been presented. C. Yunyun et al. [96], have studied a new double-rotor stator PMSM for HEVs. In this particular design topology, the stator and inner rotor have windings and magnets. While, the middle rotor is only an iron core. Due to simple structure of the middle rotor, there is no need for a cooling system.

Flux-switching PMSMs (FSPMSMs) have also recently exhibited to be promising candidates for HEV/EVs [103111]. They offer high power and torque densities, high efficiency at low-speed operations, compact structure, and lower torque ripples. The aforementioned features can be advanced by employing double stator/rotor structures. L. Zhou, and W. Hua [103], have studied the influence of the stator teeth number on the magnet field couplings of co-axial dual-mechanical-port FSPMSMs for fuel-based extendedrange electric vehicles. They have used a double stator and rotor topology to determine the best possible electromagnetic capability. In [104-107], the researchers have proposed the use of FSPMSMs for in-wheel direct drive applications.

Table II illustrates an overview of the main characteristics of each aforementioned PMSM topologies. In this table, the red and green colors show main drawbacks/advantages of each factor for each topology. It can be seen that IPMSMs have been widely used in the traction application market because of their compactness, overland torque capability (which brings reliability), high output power, and low material cost. Additionally, the research and development (R\&D) on IPMSMs has a mature and rich feature, specifically in HEV/EVs. Due to complexity, cost and immature R\&D of DSRPMSMs, they are not widely employed.

Yet, despite their very high electromagnetic-based performance such as torque, output power, and efficiency. It is worthy to mention that the iron loss in both the stator and rotor of IPMSMs is higher than in SPMSMs at maximum and minimum speed operations. While, the SPMSMs have higher iron loss at medium speed operations. The SPMSMs have higher magnet loss at all speed operations. 
TABLE II.

COMPARATIVE OVERVIEW OF DIFFERENT PMSM TOPOLOGIES

\begin{tabular}{|l|l|l|l|l|}
\hline $\begin{array}{l}\text { Factor/ } \\
\text { Topology }\end{array}$ & IPMSM & SPMSM & DSRPMSM & FSPMSM \\
\hline PM mass & Low & Medium & High & Medium \\
\hline Copper mass & Medium & Medium & High & Low \\
\hline Rotor mass & Low & High & Very high & Medium \\
\hline Stator mass & Medium & High & Very high & Low \\
\hline Total mass & Medium & Medium & High & Low \\
\hline Compactness & Medium & High & Medium & Very high \\
\hline EMF & Medium & High & Very high & High \\
\hline Average torque & Medium & Medium & High & Low \\
\hline Torque ripple & High & Low & Medium & Low \\
\hline $\begin{array}{l}\text { Overload } \\
\text { torque }\end{array}$ & High & Low & High & Medium \\
\hline Cogging torque & Low & Low & High & Medium \\
\hline Output power & High & Low & Very high & Medium \\
\hline Efficiency & Medium & High & Very high & High \\
\hline Reliability & High & High & Medium & Medium \\
\hline Complexity & Medium & Low & High & Medium \\
\hline $\begin{array}{l}\text { Temperature } \\
\text { rise }\end{array}$ & Medium & Low & Medium & Very high \\
\hline Cooling system & Medium & Low & High & High \\
\hline Material cost & Low & Medium & High & Medium \\
\hline R\&D interest & Medium & Low & Very high & High \\
\hline Market interest & $\begin{array}{l}\text { Very } \\
\text { high }\end{array}$ & Low & High & Medium \\
\hline
\end{tabular}

\section{b. Switched Reluctance Motors (SRM)s}

SRMs are a well-known type of motor that may be employed in HEV/EVs in the future. Their main benefit is independency from the permanent magnets, and therefore much lower associated material costs. Because of their exceptional robustness and reliability within fault tolerant and harsh environment operations. Nowadays, SRMs offer:

- Low cost

- Competitive torque

- Good Efficiency during wide operation modes

- Rotor robustness

- Ability to work in high temperature environments. For example, next to an internal combustion engine

However, they suffer high torque ripple, low torque and power densities, low efficiency, and high acoustic noise, originated from very high harmonic components, which is a considerable characteristic for AE-related applications [112120]. In [112], the authors have offered a survey on the literature published in modelling, design optimization of SRMs. M. Kawa et al. [113] have studied noise, vibration and harshness reduction of SRM using some novel current profiling methods, while the efficiency remains unchanged. In reference [114], the impact of deferent rotor pole numbers for a segmented-rotor SRM has been studied. Their target was reaching higher efficiency at the widest possible operation modes. Also, the idea of rotor segmentation has been investigated in [115]. The use of in-wheel SRMs is also discussed in [116-118]. The authors have employed sensitivity analysis to identify the most significant design variables for optimization targets. K. Kiyota et al. [119] have worked on torque enhancement of the SRMs using an optimal ratio of outer diameter and axial length.

C. Gan et al. [120], have illustrated a technical overview on machine topologies and control techniques for low-noise SRM drives. They have studied how to reduce radial vibration and torque ripples, afterward, the authors have categorized the techniques to enhance the motor's noise by:

- Machine topology improvement

- Control strategy design

\section{c. Induction Motors (IM)s}

The state-of-the-art is very mature in design, optimization, as well as control strategy [121-132]. The IMs can be categorized in the following types:

- Asynchronous (or doubly-fed)

- Squirrel-cage

Both IMs topologies offer the following advantages in $\mathrm{HEV} / \mathrm{EV}$ :

- Simple construction

- Inexpensive

- High robustness

- Middle class maintenance requirement

- Reliability

- Low copper and iron losses

- High Efficiency (appx. 75\% for a wide speed range and over $96 \%$ at high speed operations)

IMs have heat sources in both stator and rotor cores, therefore, the cooling system requirements can be one of their disadvantages and affects the temperature distribution [121-122]. A longer axial length is needed to provide similar torque and efficiency as the other machine technologies (such as PMSMs and SRMs) [123-124]. This means that the IMs fall behind in compactness and low weight features which are important in HEC/EVs applications.

In reference [125], the researchers have analyzed different machine technologies such as IPM and a coppercage IM in 2004 Prius HEV. They have found out the IM design at high torque density is very sensitive to saturation, and thus, they have suggested detailed finite-element models must be used to develop a competitive design. In another study [126], the authors have provided the power loss and efficiency maps for IPMSM, SPMSM, and IM. The results show the power loss variation of IMs is the largest in both low and high-speed operations in comparison with PMSM models. Also, the energy consumption has been penalized due to the cage losses both at low and high speeds. Nevertheless, the IM has a very good overload capability. M. Popescu et al. [127], have designed an IM, in which the main design parameters are equivalent to Tesla S 60 traction motor. Two different winding topologies, hairpin and stranded, have been used to evaluate their impacts on the 
efficiency and torque. In [128], a $20 \mathrm{~kW}$ high temperature superconducting induction-synchronous Machine (HTSISM) has developed. In this study, they have examined the HTS-ISM with partial and full superconducting HTS-ISM, in which an efficiency of $92.3 \%$ at maximum power has reported. More studies on linear IMs applied in electrified powertrains can be found in [129-131].

Table III presents traction application-oriented characteristics of the abovementioned motors. The torquespeed profile of the electric motors signifies the performance of the motor, and thus, knowing the behavior of it during different driving conditions helps the vehicle manufacturers to select the best possible motor type. Acceleration requires a high starting torque property which can be found in PMSMs and SRMs. Higher electromagnetic-based capability, such as higher power and torque densities, allows the PMSMs to perform better within a hill climbing driving cycle. Whereas, the high-speed overload of SRMs has considerably highlighted this type of motor among researchers. The high torque ripple of IMs and SRMs is due to Maxwell harmonic forces and exciting forces (produced by the slot per pole interactions), the open-slot configuration causes slot ripple harmonics which increases the motor losses as well as vibrations and noise. Although, these effects can be reduced using alternative techniques such as in [132141], however, PMSMs offer lower vibrations and noise because of low harmonic distortion in the magnetomotive forces. The torque-speed profile of PMSMs have shown a better capability in comparison with other types. The main highlight of SRMs is overload capability offering excessive load and subjected to very rigid duty. Most of the electrified powertrains work with more than one motor (often two/ four electric motors for a medium size vehicle) for loading management. Hence, they should be capable of operating in parallel and mechanically coupled, in which the main characteristics (such as torque-speed-current property) meet the requirements. IMs present a considerable potential at running together because of simple and inexpensive mechanical and control designs. Also, the PMSMs indicate maturing capacity in recent years, where they were mechanically coupled and easily controlled. Efficiency of the electric motors and entire powertrain is one the main advantages of EVs toward internal combustion engines (ICE)s and conventional fuel-based powertrains. To ensure that the electrified powertrains operate at high efficiency, the designers must evaluate their motors under different torquespeed-efficiency profiles. The efficiency of the coupled motors should be high at a wide range of speed profiles at low-speed, medium-speed, high-speed, peak torque, and starting speed (torque). Of course, each type of motor has its own efficiency profile, but the PMSMs brought better efficiency in comparison to other in general [58]. Due to the importance of the vehicle weight and limited space in the powertrains, the motor size should be considered. The PMSMs offer the highest compactness and lowest weight at the same range of power. Despite the fact PMSMs have illustrated the best electromagnetic-related performance, they are also subjected to a high temperature-rise due to the magnets. In addition, IMs have also shown a high temperature-rise because of having two sources of heat in both stator and rotor. In transportation applications, the reliability requirements are vital because of safety issues. When it comes to the reliability there are many technical factors such as temperature-rise, self-relieving, voltage fluctuations, and temporary disturbance in supply capabilities. Self-relieving capability relies on the torquespeed-efficiency profile; any instant fall or increase in load requires an excessive overloading feature for self-protecting under aggressive driving. Within the acceleration time, higher current inrushes produce rapid voltage fluctuations. Therefore, the coupled motor's performance must be resistive toward these fluctuations. Low disturbances in supply affect the overall performance of the motors, and thus, the coupled motors must be capable to overcome this temporary duty. Another main advantage of SRMs is their high reliability in comparison with IMs and PMSMs. Critical temperature-rise in both PMSMs and IMs result in material failures (for example in insulation) which requires more maintenances in comparison with SRMs. The PMSMs are the most expensive motors because of the rare-earth magnet (such as $\mathrm{NdFeB}$ ) cost and cooling system dependence to the critical temperature-rise. The cheapest motors are the SRMs. The IMs and PMSMs due to mature R\&D in both design and their control drives have earned more interest in the market. While, the SRMs are still under R\&D for traction applications.

TABLE III.

COMPARATIVE OVERVIEW OF TRACTION EMs

\begin{tabular}{|c|c|c|c|}
\hline Factors/EM & PMSMs & SRMs & IMs \\
\hline Max. torque & high & low & medium \\
\hline Starting torque & high & high & medium \\
\hline Torque @ hill climbing & high & low & medium \\
\hline Torque ripple & medium & high & high \\
\hline Torque Density & high & Medium & Medium \\
\hline High-speed overload & medium & high & low \\
\hline Parallel running capability & high & medium & high \\
\hline Power density & high* & low & medium \\
\hline Efficiency @ low-speed & high & low & medium \\
\hline Efficiency @ medi-speed & high* & low & high \\
\hline Efficiency @ high-speed & high & high* & high \\
\hline Efficiency @ peak torque & high & medium & low \\
\hline Compactness & high & low & low \\
\hline Weight & low & medium & high \\
\hline Maintenance & high & low & high \\
\hline Temperature-rise & high & low & high \\
\hline Self-relieving capability & high & low & medium \\
\hline Reliability & medium & high & low \\
\hline Maintenance & high & low & high \\
\hline Cost & high & low & medium \\
\hline Traction market interest & high & low & medium \\
\hline
\end{tabular}

\section{APPLIED SA METHODS IN EV/HEV POWERTRAINS}

A. Footprint of Driving Torque in Electric Motors 
The main characteristics of electric motors rely on the torque-speed-efficiency profiles which are discussed in more detail in this section. Dealing with these profiles is one of the critical design's issues for transportation applications due to instant variations of speed, high torque demand, and high safety requirements. These profiles are presenting, directly and indirectly, a few important parameters under driving conditions:

- Starting or breakaway torque: in this operation mode, the maximum acceleration is reachable.

- Pull-in and pull-out torque: within the low speed driving range, the pull-in torque can be produced. The pull-out torque is not limited to any specific speed range, and thus, it is available over the entire speed range, during momentary overloads, load fluctuations exceeding the load torque, or abrupt voltage fluctuations.

- Full-load torque: this torque should be produced as near as possible to the synchronous speed, often occurs within the accelerating phase of driving.

- High-efficiency footprints: high efficiency areas under wide range of speed and torque property, depending on the type of motor.

- Temperature-rise: a safety requirement of the electric motor is mainly subjected to temperaturerise and demagnetization which lead to critical failures such as high copper loss and may even lead to a stall condition.

- Tractive force.

As presented in Figure 2, the nonlinear behavior of the torque profiles for different types of electric motors (discussed in section II) with comparative parameters are discussed. For IPMSMs and SPMSMs, the highest torque property (black curve, T8) is shown with a constant torque range from point $a-c$. The medium overload capacity of torque is also presented with dashed black curve. The green and red areas show the high efficiency concentrations for IPMSMs [77][80-81][84][85] [142-144] and SPMSMs [89][91][93][145-152], respectively. With respect to the literature, the SPMSMs provides high efficiency at higher torque T3-T6 (near to rated speed). However, IPMSMs offer a high efficiency performance at lower torque T1-T4 with slightly wider speed range. Although, the average torque of FSPMSMs is slightly lower than other PMSMs, they still produce higher average torque than SRMs and IMs. Their maximum efficiency footprint (grey pattern box) is near to the base speed $\left(c^{*}\right)$, which begins to degrade within parallel operation in HEV/EV powertrains (or accelerating phase). In DSRPMSMs (light blue pattern box), researchers have widely reported [153-160] a torque property improvement (T9) which allows the motor to offer higher driving torque and torque density among other motor topologies. Due its close behavior to IPMSMs, SPMSMs, and FSPMSMs, its

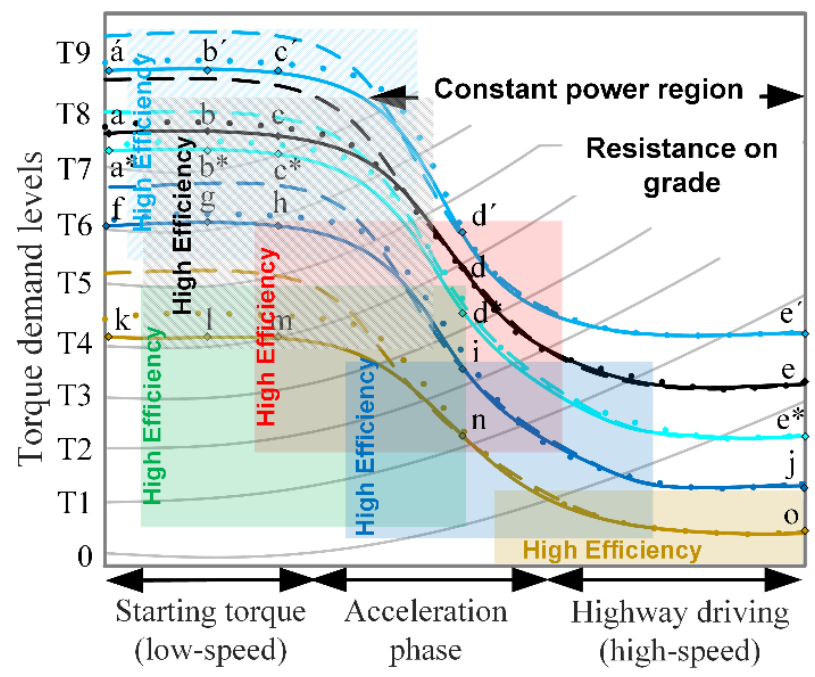

FIGURE 2. Comparative driving torque-speed-efficiency footprints of different electric motors. Notes. The light blue presents the DSRPMSM's torque level (curve) and high efficiency (region) concentration. The turquoise blue represents the FSPMSM's torque. Black color indicates the PMSM's torque level and high efficiency concentration; among the different configurations. The green and red boxes show the high efficiency concentrations for both SPMSMs and IPMSMs. The dark blue color exhibits the IMs performance; the brown color demonstrates SRMs' torque and high efficiency.

operations modes are marked as $a^{\prime}-c^{\prime}$ (constant torque), $d^{\prime}$ (full-load or rated torque), and $e^{\prime}$ (speed boosting time or highway driving). The full-load torque capacities of all four PMSMs are correspondingly indicated by $d$ (for both IPMSMs and SPMSMs), $d^{\prime}$, and $d^{*}$. All the high-efficiency areas for the PMSMs topologies have an efficiency higher than $\eta \geq 90 \%$. Also, they have all relatively medium overload capacity under high-torque operation. The IMs (dark blue) with medium torque level $(\approx \mathrm{T} 6)$, where the highest constant torque is obtainable between $f$ - $h$ points. They normally offer high efficiency (blue area) with approximately $\eta \geq 85 \%$ at lower torque within T1-T2, at rated speed. Additionally, they offer lower full-load torque (T4) in comparison with all PMSM-related topologies. As shown by the dashed dark blue curve, they suffer from a low overload capacity which is the lowest among all the motor topologies discussed in this study [161-170]. In SRMs (brown), the maximum torque and torque density are the lowest among all the motors, however, they can offer a very high overload capacity (dashed brown curve) which is the highest among others. The available fullload torque of SRMs is also the lowest $(\approx \mathrm{T} 2)$. Moreover, their high-efficiency $\eta \geq 85 \%$ footprint is unique in that it is reachable at high speeds within high-way driving mode (see light brown area)[116][138][171-185]. The grey curves are the relative tractive forces (in N. $\mathrm{kg}^{-1}$ ) during driving or motor operation as a function of speed. The temperature-rise affects the torque profile [186-191] of all electric motors mentioned. For example, lower temperature leads to a slightly larger torque property which are shown as dotted curves.

Note that when a motor is loaded with a constant torque, it is partially demagnetized, which draws more current to generate the demand torque. The increased current will 
introduce higher copper loss, and finally results in temperature-rise. Temperature rise of the electric motors, especially in PMSMs and IMs, is one the parameters which highly affects the safety requirement. To this end, all design parameters somehow have influence on the torque-speedefficiency profile of the motor. Therefore, careful sensitivity analysis methods should be applied, when the component is subjected to run an electrified powertrain.

\section{B. Applied SA Methods in Electric Motors for HEV/EVS}

Engineers worldwide use sensitivity analyses for optimising electric motors in electrified powertrains [192209], however, depending on their mathematical skills they employ either local or global methods. As described in Section III-A, most of the design variables and their interactions have influence on the torque-speed-efficiency profile of the motors. The SA methods worldwide performed on the motors in electrified powertrains are mainly localbased methods, in which all derivatives are computed at a single point which highly limits the search space explorations. Assuming this is a nominal value in the entire hyperspace of the design variables, this approach is known as one-at-a-time (OAT); the failure reasons of the OATbased method is also reported in [210]. There are other more advanced local SA approaches, where each design variables' importance relies on the derivative of a different order of the objectives (torque and efficiency as outputs) for that individual variable, these approaches are known as ANOVA (one-way to n-way), design of experiment, and linear regression. These local-based SA methods have brought rapid, simple, and more accurate SAs than OATs (including partial derivatives approaches) [211-212]. Although, they are informatic on providing a variables' interactions, the fact that they only explore the neighborhoods of the nominal value in the search space should not be ignored unless the model is linear (which is not the case of the torque-speedefficiency profile in the motors). Due to the torque-speedefficiency nature of electric motors, where the model is nonlinear and the property of both torque and efficiency is unclear, global SA methods should be employed. Instead of relying on only derivative values estimated at a single point (referring to the nominal value). These methods are mathematically more sophisticated, time-consuming and expensive to be implemented, however the cost brings high robustness in knowing the design variables' global impact (including their interactions) on the variance of the torquespeed-efficiency profiles.

\section{Case Studies Discussion}

Researchers have applied SA methods to electric motors running in electrified powertrains. Among them, many have employed OATs [192-195], where the methodology limitations explained in Section B will provide unreliable results. They only work if targeting a certain linear condition of the model with some pre-defined assumptions. For example, when the motor running under component level without any regenerative torque, constant torque range (e.g. between point a-b, Figure 2), and all other environmental factors such as road slope (which will have an influence on loading rates) are ignored. This section discusses the SA methods such as OAT, LSA, and GSA performed in electric motors for both component and powertrain levels.

\section{C1. OAT-based SA Case Studies}

The OAT-based SA method is based on a simple mathematical formulation which considers the initial samples $x_{\text {ini }}$ and its sensitive quantity by $x^{+}$. The method computes the model through varying the inputs once at a time from their initial to the sensitive quantities. The SA model can be given as:

$$
\Delta_{i}^{+} y_{1}=g\left(x_{i}+\Delta x_{i}^{+}, x_{\sim i}^{i n i}\right)-g\left(x^{i n i}\right)
$$

where $x_{i}+\Delta x_{i}^{+}, x_{\sim i}^{i n i}$ is the sample point that can be varied toward the sensitive quantity; $\Delta_{i}^{+} y_{1}$ are the affected outputs corresponding the input's variations in the model.

In [192] the researchers have apparently employed an OAT method because the nominal values are considered, and the interactions among the design variables are ignored. They studied the most impactful cooling-related design parameters on temperature-rise of PMSMs, while the power, thermal constraints, and efficiency were fixed. For simplicity, the OAT method has performed the variation of only driving torque within two phases, high-speed, lowtorque and low-speed, high-torque, where the researchers have assumed the model behavior is linear, although it is not in reality. The accelerating phase, which is the most challenging phase because of its nonlinearity, was also neglected. Moreover, the loading heat distributions were numerically defined, whereas they vary nonlinearly depending the drive cycle, road slope, wind speed etc. Due to these pre-defined heat distributions, the OAT fails offering practical values such as "over $45 \%$ power improvement". As the authors have mentioned, "The impact of improvements depends on the operating conditions of the electric motor.", while these operating points are limited by pre-defining the heat load distributions which finally results in unrealistic values for power and efficiency.

In another work [193], the authors have presented SAbased component level study for a permanent-magnetassisted SRM. Sizing-related design variables, such as magnet size, airgap, and flux barriers size, were studied to improve the torque profile. Although, the FEM-based results show promising conclusions, they are only limited to the component test bench. As the SRM has been designed to be operated in an EV, the sensitivities must be computed under real loading conditions, where the demand torque is varying nonlinearly toward the drive cycle. Such a rigid test environment can be subjected to demagnetization and critical temperature-rise, in addition, the variables' interactions are all ignored in this study. Additionally, the design variables' exploration is limited to the nominal values and their neighborhoods. Therefore, the OAT method is chosen.

In [194], the researchers have used the OAT method for SA of a SRM in a HEV. They have introduced six 
geometrical-based design variables and presented the influence of these parameters (based on nominal values) on the torque profile. The report suffers in both visually and quantitatively-related statistical information. Also, variables' interactions are not given.

\section{C2. LSA Case Studies}

The most common LSA method is a differential-based approach, in which the local variations allow the prediction of the gradient based on Taylor series expansion of the output model. Its decomposed model can be given:

$$
\begin{aligned}
& \Delta y=g\left(x^{+}\right)-g\left(x^{i n i}\right)=\sum_{i=1}^{n} \frac{\partial g\left(x^{i n i}\right)}{\partial x_{j}}\left(x_{j}^{+}-x_{j}^{i n i}\right)+ \\
& 0.5 \sum_{j=1}^{n} \sum_{k=1}^{n} \frac{\partial^{2} g\left(x^{i n i}\right)}{\partial x_{j} \partial x_{k}}\left(x_{j}^{+}-x_{j}^{i n i}\right)\left(x_{k}^{+}-x_{k}^{i n i}\right)+ \\
& o\left(\left\|x^{+}-x^{i n i}\right\|^{2}\right)
\end{aligned}
$$

where $y$ is the model output (or estimation), $x^{+}$is the sensitivity input (variable), $x^{\text {ini }}$ is the initial valued variable, the $j$ and $k$ are the initial and higher-order variable distributions for individual samples.

To slightly explore the search space of the variables, engineers have used design of experiments associated to derivatives. There are variety of design functions which may be employed, such as full factorial, central composite, orthogonal, and Taguchi design functions, with different computational costs. For instance, when there are five design variables, a three-level design of full factorial function will generate $y=y\left(x_{1}, x_{2}, x_{3}, \ldots, x_{5}\right)=3^{5}=243$ operating points in the search space of the design variables associated with the objectives variance (torque-speed-efficiency profile), these points will be coded between $y=y(0,0,0,0,0)$ to $y=$ $y(1,1,1,1,1)$. Due to simplicity of implementation and the computationally cost effectiveness of these methods, researchers have widely applied them in electrified powertrains, particularly at the component level.

In [196], the researchers have aimed to evaluate the SA of geometrical-related design variables on the torque profile, its ripples, torque density, and efficiency of an in-wheel SRM in an EV. They employed seven design variables to be performed in the orthogonal design function with computational cost of 2,097,152, which are generated the variable search space. They have discussed the influence of each variable on the pre-defined objectives. Although, adequate operating points are employed in the neighborhoods of the nominal/base values in comparison with the OAT method with 64 points. When there are multiple designs, variables and objectives in the model, decision making on the overall impact of each variable on every individual objective could be reached if the variables interactions were reported. To tackle this issue, the researchers have manually pre-defined a weighted pattern to recognize the importance of each of those four objectives. Although, having this weighted pattern might be informative, an appropriate approach is to systematically consider the interactions, in which all the weights vary between 0 to 1 . This way, a complete image of variables' interactions on each objective can be considered, which comes with additional computational cost. In another similar work, [197], the author has employed a Taguchi design function to evaluate sensitivity of the sizing-related design variables on a speed range, torque profile for an SRM. The report shows the significance of each design variable along with their interactions for a component level study. By which they mean that operating points are not extracted from a suitable drive cycle, and the design variables search space is limited to an orthogonal pattern which cannot explore the entire search space.

In [198], the authors have used a standard drive cycle (known as Artemis [214]) to examine real-case operating points of the electrified vehicle. They have split the torque profile to five regions and two constraints for lowering the computational cost. By defining a set of design variables linked to the PMSM used, they have proposed a software tool based on both fractional factorial and Taguchi design functions for the SAs targets. Although, the work framework and real-case approaching technique (due to operating points generated using drive cycle) used are appreciable, the report suffers in illustrating the design variables impact and their interactions on the objectives. Also, more detail could be provided regarding the mathematical definitions (e.g. partial derivative of different order of the objectives) and/or the solver implemented in the software to perform SA. Based on the report published, it is hard to judge whether the SA was performed in a component or system level.

Y. P. Yang and D. S. Chuang [200], have studied using a simplified partial derivatives-based LSA method to study the influence of 13 geometrical-focused design variables on torque, speed and efficiency (as objectives) for a modern DSRSPMSM in an EV powertrain. They have presented the variables influence on each objective, however the demonstration of the design variables' interactions, either visually or quantitatively is neglected. Hence, the authors have ignored to provide either mathematical definition or any scenario for selecting the most sensitive variables.

Z. Xiang et al. [199], have presented a comprehensive partial derivatives-based SA in order to categorize the geometrical-focused variables into three levels for a FSPMSM, in a HEV powertrain. The design variables are subjected to a range of nominal values which limit the search space of each variable. To select the design variables with mild- and strong-sensitive levels and ignore those with no sensitive level, they have employed a simple algebraic weighted-based expression. Also, the chosen design variables interactions were shown using correlation matrix. The SA methodology employed is known as a typical LSA, in which input variables significance and their interactions can be studied. There are some drawbacks using this LSA method, such as:

- The SA results for the torque profile may be informative, although, robust SA results can only be achieved when the model is linear. 
- The exploration of the search spaces of the design variables are limited to the nominal values and their neighborhoods.

\section{C3. GSA Case Studies}

Due to engineering and manufacturability reasons, each pre-defined controllable variable $x_{\mathrm{i}}$ is given an uncertainty range $\left(x_{i, \min }\right.$ to $\left.x_{i, \max }\right)$. The main advantage of the quasirandom sequence (sampling matrices) is its size reduction to $(n, k)$. Unlike the random sequences with the size of $(n, 2 k)$ for $A_{1}$ and $A_{2}$ matrices, the quasi-random samples always learn the position of the past samples $(i-1)$ and load the gaps between those points. A thousand samples, $n=1000$, are randomly generated to fill each variable matrix of $(n, k)$ dimension for both sampled and re-sampled matrices:

$$
A_{1}=\left[\begin{array}{cccc}
x_{11} & x_{12} & \ldots & x_{1 k} \\
x_{21} & x_{22} & \ldots & x_{2 k} \\
\vdots & \vdots & \ldots & \vdots \\
x_{n 1} & x_{n 2} & \ldots & x_{n k}
\end{array}\right], A_{2}=\left[\begin{array}{cccc}
\dot{x}_{11} & \dot{x}_{12} & \ldots & \dot{x}_{1 k} \\
\dot{x}_{21} & \dot{x}_{22} & \ldots & \dot{x}_{2 k} \\
\vdots & \vdots & \ldots & \vdots \\
\dot{x}_{n 1} & \dot{x}_{n 2} & \ldots & \dot{x}_{n k}
\end{array}\right]
$$

$n$ and $k$ are the number of samples (or simulations) for the Monte-Carlo-based algorithm and the number of variables. As the above $A_{1}$ and $A_{2}$ matrices are independently defined, therefore a joint probability density can be given:

$$
P\left(x_{1}, x_{2}, \ldots, x_{k}\right)=\prod_{i=1}^{k} p_{i}\left(x_{i}\right)
$$

where $i$ subscript indicates the number of the variable. The mean of the objectives (outputs) is a matrix composed of the number of objectives at each iteration:

$$
E\left(\vec{y}_{z}\right)=\left[\begin{array}{c}
y_{1} \\
\vdots \\
y_{z}
\end{array}\right]
$$

where the mean of the objectives (Eq. 5) is:

$$
\begin{aligned}
& E\left(\vec{y}_{z}\right)= \\
& {\left[\begin{array}{ccc}
\iint \ldots \int\left[f_{1}\left(x_{1}, x_{2}, \ldots, x_{k}\right) P_{1}\left(x_{1}, x_{2}, \ldots, x_{k}\right)\right] & d x_{i} \\
\vdots & \\
\iint \ldots \int\left[f_{z}\left(x_{1}, x_{2}, \ldots, x_{k}\right) P_{z}\left(x_{1}, x_{2}, \ldots, x_{k}\right)\right] & d x_{i}
\end{array}\right]}
\end{aligned}
$$

and the variance of the objectives $y_{\mathrm{i}}$ can be:

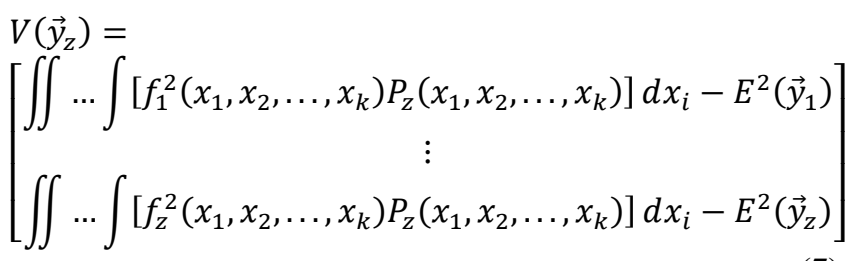

where $z$ subscripts address the individual objectives (outputs) that are $z=2$ for this study. Let the variables to be partitioned into two groups, the test $u_{i}=\left(x_{i, 1}, x_{i, 2}, \ldots, x_{i, m}\right)$ and the remain $v_{j, k}=\left(x_{j, 1}, x_{j, 2}, \ldots, x_{j, k-m}\right)$ subsets. The remaining subset corresponds to any generic variables which is fixed to a value. The main indices effect of the $u$ subset on the variance of the objectives (Eq. 7) by Sobol's method [218] is:

$$
U_{v_{i, j, k, z}}=\left[\begin{array}{c}
\iint \ldots \int f_{1}\left(u_{i}, v_{j, k}\right) f_{1}\left(u_{i}^{\prime}, v_{j, k}\right) d u_{i} d u_{i}^{\prime} d v_{j, k} \\
\vdots \\
\iint \ldots \int f_{z}\left(u_{i}, v_{j, k}\right) f_{z}\left(u_{i}^{\prime}, v_{j, k}\right) d u_{i} d u_{i}^{\prime} d v_{j, k}
\end{array}\right]
$$

where $j$ subscript presents the number of the remain variable vector. To drive the Eq. 8 formula into the Monte-Carlobased algorithm, its quantities will be computed using:

$$
\begin{gathered}
\widehat{U}_{v_{z}}= \\
{\left[\begin{array}{c}
\frac{1}{n-1} \sum_{r=1}^{n} f_{1}\left(x_{r i_{1}}, x_{r i_{2}}, \ldots, x_{r i_{m}}, x_{r l_{1}}, x_{r l_{2}}, \ldots, x_{r l_{k-m}}\right) \\
. f_{1}\left(x_{r i_{1}}^{\prime}, x_{r i_{2}}^{\prime}, \ldots, x_{r i_{m}}^{\prime}, x_{r l_{1}}, x_{r l_{2}}, \ldots, x_{r l_{k-m}}\right) \\
\vdots \\
\frac{1}{n-1} \sum_{r=1}^{n} f_{z}\left(x_{r i_{1}}, x_{r i_{2}}, \ldots, x_{r i_{m}}, x_{r l_{1}}, x_{r l_{2}}, \ldots, x_{r l_{k-m}}\right) \\
. f_{z}\left(x_{r i_{1}}^{\prime}, x_{r i_{2}}^{\prime}, \ldots, x_{r i_{m}}^{\prime}, x_{r l_{1}}, x_{r l_{2}}, \ldots, x_{r l_{k-m}}\right)
\end{array}\right]}
\end{gathered}
$$

where $r i$ subscripts and prim superscripts demonstrate the number of re-shaped samples in the algorithm. Therefore, the variance is decomposed using:

$$
V\left(\vec{y}_{z}\right)=\left[\begin{array}{c}
\sum_{i} V_{i, 1}+\sum_{i} \sum_{j>i} V_{i j, 1}+\ldots+V_{12 \ldots k, 1} \\
\vdots \\
\sum_{i} V_{i, z}+\sum_{i} \sum_{j>i} V_{i j, z}+\ldots+V_{12 \ldots k, z}
\end{array}\right]
$$

where $V_{\mathrm{i}, \mathrm{z}}=V\left(E\left(Y_{\mathrm{z}} \mid x_{\mathrm{i}}\right)\right)$ and $V_{\mathrm{ij}, \mathrm{z}}=V\left(E\left(Y_{\mathrm{z}} \mid x_{\mathrm{i}}, x_{\mathrm{j}}\right)\right)-V_{\mathrm{i}, \mathrm{z}}-$ $V_{\mathrm{j}}$. The total indices effects are rewritten as:

$$
\hat{S}_{j, z}^{\text {tot }}=\left[\begin{array}{c}
1-\frac{\left(\widehat{U}_{v_{i}, j, k, 1}-\hat{E}_{1}^{2}\left(y_{1}\right)\right.}{V\left(y_{1}\right)} \\
\vdots \\
1-\frac{\left(\widehat{U}_{v_{i}, j, k, z}-\hat{E}_{Z}^{2}\left(y_{z}\right)\right)}{V\left(y_{z}\right)}
\end{array}\right]
$$

Turning to the SA methods reported in Table I, due to complexity and limitations, the use of GSA methods is nearly a quarter of LSA-based methods (including OAT) applied in AE. In GSAs, an appropriate wide neighborhood of initial nominal values should be credible, when the corresponding interval of inferences is narrow enough to be useful [214]. To perform GSA, there are well-known methods such as nonlinear regression [215], regressionbased Monte Carlo [216], variance-based Monte Carlo [217], global derivative-based measures (known as Sobol) [218], density-based indices method [219], moment-independent method [220-221], variogram-based [222], etc. These methods can perform robust and valid SA while model's characteristic have nonlinearities and interactions.

$\mathrm{X}$. Zhu et al. [202] have presented a variance-based GSA for a speed range in-wheel FSPMSM, where the model objective is high torque capability to overcome frequent acceleration and overload climbing operations. They have selected multiple sizing-focused design parameters for GSA. The same authors in another work [203], have also worked on different topologies of IPMSMs, where flux-intensifying, two single-layer PM flux-intensifying and double-layer PM flux-intensifying motors concepts are introduced. Like their previous work, they have defined several geometricalfocused design variables to perform a variance-based GSA. Both studies have shown considerable results, although, they 
have presented the variables on the torque and torque ripple, the variables interactions cannot be found in the report.

O. Sundstrom et al. [204], have studied a system level regression-based GSA for $24 \mathrm{~kW}$ electric motor in a HEV powertrain. They have used a least squares solver for six different drive cycles which is considerable. Moreover, they have provided the torque-speed-efficiency profile of the electric motor. Although, they have ignored giving the type of electric motor used but based on the footprint given in Fig. 2. We can say that a SPMSM was implemented. They have also disregarded to show either visual or quantitative variable interactions for the methodology employed. Note that GSA based on nonlinear regression which is often performed using a nonlinear least squares solver to estimate the solution of a set of derivative equations have some advantages using this approach:

- The entire search space of the design variables can be explored, limited to the variables' intervals (predefined).

- The averaged impact of each design variable will be given.

- Computationally cost-effective in comparison with other GSA methods.

- And simpler implementation.

\section{NUMERICAL-BASED DISCUSSION AND VERIFICATION}

The performance evaluation of the studied SA methods is provided in this section, where the third-generation TOYOTA Prius is re-modelled for simulation purposes. The targeted EM is well studied in [224-229]. The main specifications of the EM are given in Table IV. The designed EM has offered a maximum power of $60 \mathrm{~kW}$ within 2650$13,900 \mathrm{rpm}$, maximum torque of $200 \mathrm{~N} . \mathrm{m}$, in which the maximum RMS current is $170 \mathrm{~A}$. The efficiency of the map of the IPMSM is presented in Figure 3, under a standard urban drive cycle, known as US06, shown in white points. The maximum efficiency of $95 \%$ can be achieved between $2550-13,900 \mathrm{rpm}$. In this figure, a short instance of acceleration, pointed as area $\mathrm{A}$ in Figure 3 , is selected to evaluate all three (OAT, DOE/R, and GSA) categorized SA methods. Considering nonlinearity and transient-based simulation of the vehicle at that specific point, as presented in Figure 4, both the OAT and DOE/R methods have failed to discover the sudden change of temperature rise in the EM, i.e. magnet temperature which has resulted in an exponential increase of power loss and consequently total energy consumption estimation. It should be noted that both $\mathrm{DOE} / \mathrm{R}$ and OAT methods can deal with steady-state sensitivity analyses which are often employed for fast and useful understanding of the systems. However, the estimation errors can be, as shown in Figure 4, critical when the system runs under a dynamic transient-based simulation which offers a closer insight to what in reality the system's behavior are.
TABLE IV.

THIRD-GENERATION TOYOTA PRIUS EM SPECIFICATION

\begin{tabular}{|l|c|c|}
\hline Parameters & Unit & Value \\
\hline Stator outer diameter & $\mathrm{Mm}$ & 264 \\
\hline Stator inner diameter & $\mathrm{Mm}$ & 161.9 \\
\hline Rotor outer diameter & $\mathrm{Mm}$ & 160.4 \\
\hline Rotor inner diameter & $\mathrm{Mm}$ & 110 \\
\hline Axial length & $\mathrm{Mm}$ & 50.8 \\
\hline Airgap length & $\mathrm{Mm}$ & 0.73 \\
\hline Slot number & - & 48 \\
\hline Pole number & - & 8 \\
\hline Pole pitch & - & 6 \\
\hline Coil pitch & - & 5 \\
\hline Net fill factor & $\%$ & 56.659 \\
\hline Slot area & $\mathrm{mm}^{2}$ & 149.177 \\
\hline Number of conductors per phase & - & 176 \\
\hline Number of turns per coil & - & \\
\hline
\end{tabular}

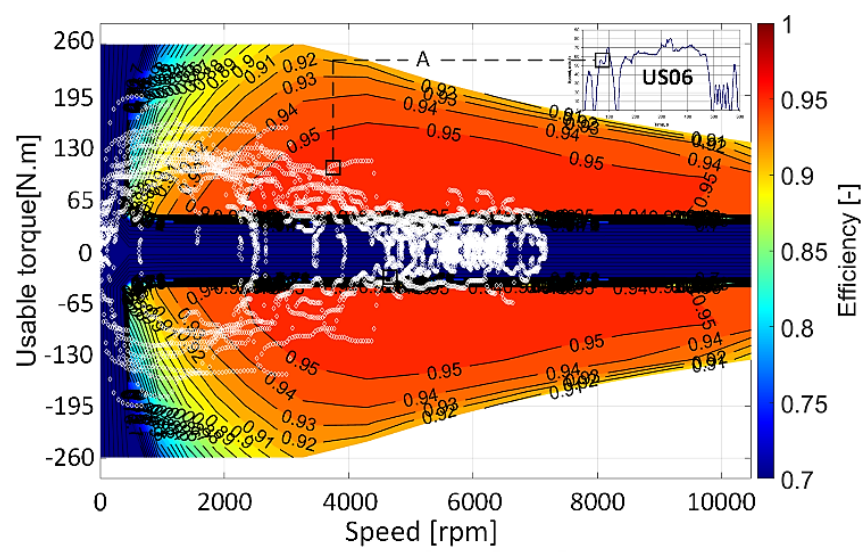

FIGURE 3. Driving torque-speed-efficiency of the third generation TOYOTA Prius electric motor under standard US06 drive cycle.

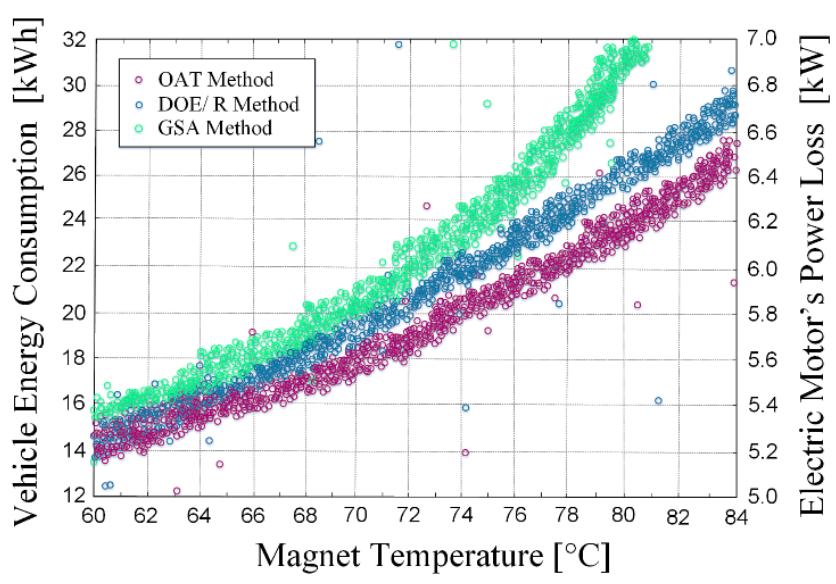

FIGURE 4. Vehicle energy consumption and electric motor power loss instant SA using different methods, of the magnet temperature at point $A$, presented in Figure 3.

\section{Recommendations and Future Notes}

Recent applied SA methods in automotive engineering illustrate that approximately $93.08 \%$ of the literatures published are based on the LSA methods, only $6.92 \%$ of the reports have employed GSAs. Although, the use of GSAbased methods has considerably grown, yet many 
researchers use LSAs because of lack of statistics-focused background, simplicity of implementation and computationally cost-effective advantages. Surprisingly, only $22.53 \%$, of applied sensitivity methods in AE-related publications, used GSA methods. Despite the fact that GSA methods have been introduced for more than two decades, there are insufficient good practices corresponding to the electric motors in the electrified powertrains. To offer an insight into the usage of any kind of SA methods among researchers, in Figure 5, a time-series-based analysis is given to present forecasting of SA methods in the future. The graph shows a linear fit with $2.76 \%$ mean absolute percentage error (MAPE); a median absolute deviation (MAD) factor is calculated to give a robust measure of the variability of a univariate sample of quantitative data, which is 60.72. Also, a mean signed deviation (MSD), which equals to 5072.12, is calculated to assess the estimation procedure, and it would often be used in conjunction with a sample version of the mean square error. Based on this information, the following formula can predict the future total number of publications, in which SA methods are employed:

$$
Y_{\text {total }}(\text { year })=1248.4+148(\text { year })
$$

Figure 6 explains the total numbers of published GSAbased article in the future based on the past decade data. The forecast illustrates a very low rate, although increasing, of usage of GSA among engineers and scientists. Because of the complexity and computational time needed for these methods. The forecasting with an acceptable MAPE $5.2626 \%$. The formula to estimate the future number of publications using GSA methods is:

$$
Y_{G S A}(\text { year })=20.78+21.082(\text { year })
$$

All the studied SA methods categorized in QAT, DOE/R, and GSA in AE-focused publications, are presented in Figure 7. The graph demonstrates that the DOE/R method leads within the next decade due to its simplicity for implementation. Also, the advanced DOE/R approaches have improved robustness in nonlinear systems. In this quadratic forecasting, the trends demonstrate exponential rise for all SA methods in AE-related publications, where the use of GSA-based methods will be the highest among others. To predict future SA-focused publications, using QAT, $\mathrm{DOE} / \mathrm{R}$, and GSA, in AE, the following set of formulas can be used:

$$
\left\{\begin{array}{c}
Y_{Q A T}=15.41-3.95(\text { year })+0.4(\text { year })^{2} \\
Y_{D O E_{/ R}}=6.68-2.54(\text { year })+0.3834(\text { year })^{2} \\
Y_{G S A}=5.77-2.835(\text { year })+0.3590(\text { year })^{2}
\end{array}\right.
$$

This forecasting is carried out based on the historic data explained in Table I.

This paper has over reviewed the SA methods applied in electric motors for the electrified powertrains. The outcomes and recommendations of the application of SAs in traction motors with respect to the footprint of the most used electric motors in the electrified powertrains. Knowing the main characteristics of these components and their model's nonlinearities help the engineers to select and perform the best sensitivity analyses methods. To do this, the torquespeed-efficiency profile (model response) and the transient temperature of the electric motors should be considered under the following conditions:

- The torque-speed-efficiency profile of the electric motor should be examined under both a wide speed range and then drive cycles. The drive cycle selection is done based on the application of the vehicle and its operating points.

- Evaluating the electric motors under real-case drive cycles, when the torque and power demands vary instantly, give a better intuition regarding the significance of design variables' search space.

- Evaluating the electric motors under real-case drive cycles, when the torque and power demands vary instantly, give a better intuition regarding the significance of design variables' search space.

- The performance of the electric motor under overload condition should be highly studied, mainly when PMSMs and IMs are selected. Depending on the safety requirements of the vehicle, the temperature-rise and demagnetization effects must be studied because they lead to stall condition.

Due to the importance of the design variables and their interactions and nonlinearities of the torque-speed-efficiency profile and their corresponding transient temperature, the main contribution of this work is to highlight the use of GSAbased methods. However, the LSA-based methods (excluding the OAT method) can be informative, particularly if some assumptions, such as electric motor linearity and additivity, will be carried out. Evidently, The OAT methods fail to explore a multi-dimensional search space, in which multiple variables are defined.

This study suggests that, although LSAs and OAT methods of SA are by far still prevailing at the time of the

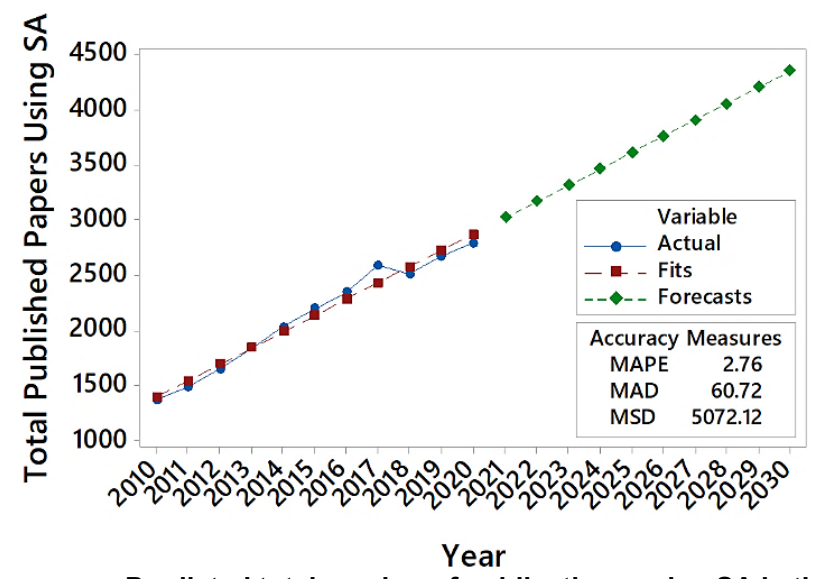

FIGURE 5. Predicted total number of publications using SA in the coming decade. 
present article, GSA-based methods might displace those techniques in future. Toward that direction, top journals could help by publishing some considerable practices of SAs in the electric motors such as [202-204].

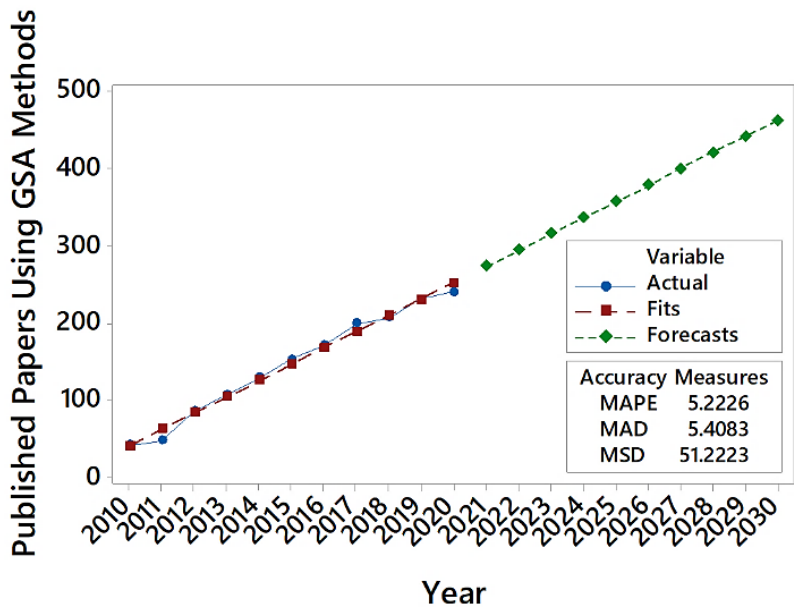

FIGURE 6. Predicted total number of publications using GSA in the coming decade.

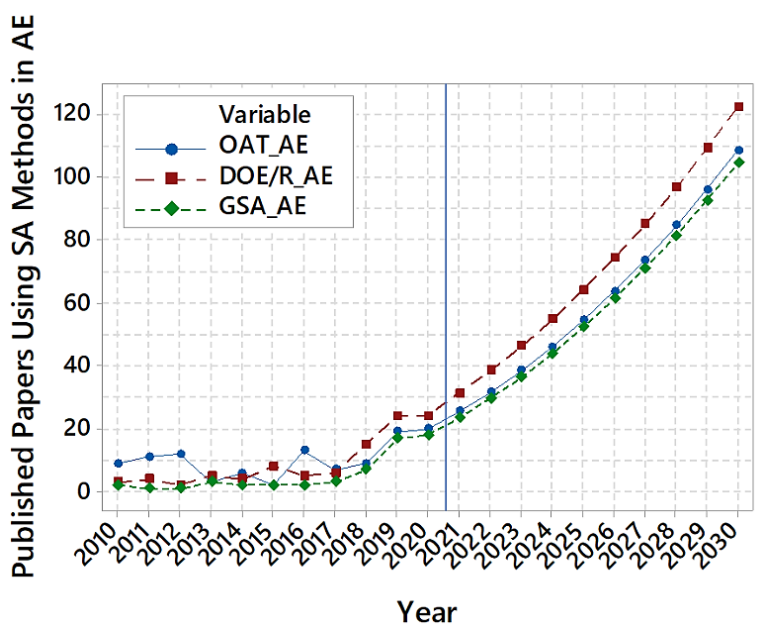

FIGURE 7. Predicted total number of publications using SA (of any kind) for AE-related applications in the coming decade.

\section{References}

[1] D. E. Reusser, W. Buytaert, and E. Zehe, "Temporal dynamics of model parameter sensitivity for computationally expensive models with the Fourier amplitude sensitivity test," Water Resources Research, Vol. 47, pp. 1-14, 2011.

[2] A. Hoare, D. G. Regan and D. P. Wilson, "Sampling and sensitivity analyses tools (SaSAT) for computational modelling," Theoretical Biology and Medical Modelling, Vo. 5, No. 4, pp. 1-18, 2008.

[3] D. L. Allaire, K. E. Willcox, "A variance-based sensitivity index function for factor prioritization," Reliability Engineering and System Safety, Vol. 107, pp. 107-114, 2012.

[4] S. Tarantolaa, D. Gatellia, T.A. Mara, "Random balance designs for the estimation of first order global sensitivity indices," Reliability Engineering and System Safety, Vol. 91, pp. 717-727, 2006.

[5] J. Cariboni, D. Gatelli, R. Liska, and A. Satelli "The role of sensitivity analysis in ecological modelling," Ecological Modelling, V.203, pp.167-182, 2007.

[6] J. Asamer, A. Graser, B. Heilmann, and M. Ruthmair, "Sensitivity analysis for energy demand estimation of electric vehicles,"
Transportation Research Part D: Transport and Environment, Vol. 46, pp. 182-199, 2016.

[7] F. Pappenberger, K. J. Beven, M. Ratto, P. Matgen, "Multi-method global sensitivity analysis of flood inundation models," Advances in Water Resources, Vol. 31, pp. 1-14, 2008.

[8] E. Plischke, E. Borgonovo, and C. L. Smith, "Global sensitivity measures from given data," European Journal of Operational Research, Vol. 226, pp. 536-550, 2013.

[9] J. Nossent, P. Elsen, and W. Bauwens, "Sobol' sensitivity analysis of a complex environmental model," Environmental Modelling \& Software, Vol. 26, pp. 1515-1525, 2011.

[10] M. Ratto, A. Pagano, P. Young, "State Dependent Parameter metamodelling and sensitivity analysis," Computer Physics Communications, Vol. 177, pp. 863-876, 2007.

[11] F. Sarrazin, F. Pianosi, T. Wagener, "Global Sensitivity Analysis of environmental models: Convergence and validation," Environmental Modelling \& Software, Vol. 79, pp. 135-152, 2016.

[12] F. Monari, and P. Strachan, "Characterization of an airflow network model by sensitivity analysis: parameter screening, fixing, prioritizing and mapping," Journal of Building Performance Simulation, Vol. 10, No. 1, pp. 17-36, 2017.

[13] H-Joo Oh, S-Chan Ahn, and J-Kuk Choi, "Sensitivity analysis for the GIS-based mapping of the ground subsidence hazard near abandoned underground coal mines," Environ Earth Sci., Vol. 64, pp. 347-358, 2011.

[14] M. M. Gomesa, A. Pirdavani, T. Brijs, and C. S. Pitombo, "Assessing the impacts of enriched information on crash prediction performance," Accident Analysis and Prevention, Vol. 122, pp. 162-171, 2019.

[15] A. Vita, V. Castorani, M. Mandolini, A. Papetti, and M. Germani, "Cost and Temperature Homogeneity Optimization of the Heating System for Composite Materials Air Press Molding," Computer-Aided Design \& Applications, Vol. 16, No. 6, pp. 1084-1097, 2019.

[16] P. Luangpaiboon, S. Boonhao, and R. Montemanni, "Steepest ant sense algorithm for parameter optimization of multi-response processes based on taguchi design," Journal of Intelligent Manufacturing, Vol. 30, No. 1, pp. 441-457, 2019.

[17] W. Zhao, A. Ma, J. Ji, X. Chen, and T. Yao, "Multi-Objective Optimization of a Double-Side Linear Vernier PM Motor Using Response Surface Method and Differential Evolution," IEEE Transactions on Industrial Electronics, DOI: 10.1109/TIE.2019.2893848, 2019.

[18] N. Naik, C. S. S. Kowshik, R. Bhat, M. Bawa, "Failure analysis of governor in diesel engine using Shainin System," Engineering Failure Analysis, Vol. 101, pp. 456-463, 2019.

[19] X. Lu, K. Xiao, G. Lei, and C. Chen, "System-Level Investigation of Traction Inverter High-Temperature Operation," SAE International, DOI:10.4271/2018-01-0464, pp. 1-6, 2018.

[20] B. Predic, M. Madic, M. Roganovic, D. Karabasevic, and D. Stanujkic, "Implementation of Computationally Efficient Taguchi Robust Design Procedure for Development of ANN Fuel Consumption Prediction Models," Transport, Vo. 33, No. 3, pp. 751-764, 2018.

[21] F. J. R. Verbruggen, and T. Hofman, "Design sensitivity analysis for heavy-duty hybrid electric trucks with a waste heat recovery system," IEEE Vehicle Power and Propulsion Conference (VPPC), DOI: 10.1109/VPPC.2017.8330939, 2017.

[22] D. S. Khang, R. R. Tan, O. M. Uy, M. A. B. Promentilla, P. D. Tuan, N. Abed, and L. F. Razona, "Design of experiments for global sensitivity analysis in life cycle assessment: The case of biodiesel in Vietnam, Resources, Conservation and Recycling, Vol. 119, pp. 1223, 2017.

[23] D. M. Wu, C. K. P. Luk, and W. Z. Fei, "Quality Control of Low-cost Electric Machines for Electric Vehicles by DOE Assisted Six Sigma DMADV Method," 7th International Conference on Power Electronics Systems and Applications (PESA), DOI: 10.1109/PESA.2017.8277740, 2017.

[24] K. Knaisch, and P. Gratzfeld, "Gaussian process surrogate model for the design of circular, planar coils used in inductive power transfer for 
electric vehicles," IET Power Electronics, Vol. 9 No. 15, pp. 27862794, 2016.

[25] S. Dey, B. Caulfield, and B. Ghosh, "Modelling uncertainty of vehicular emissions inventory: A case study of Ireland," Journal of Cleaner Production, Vol. 213, pp. 1115-1126, 2019.

[26] P. Marques, R. Garcia, L. Kulay, and F. Freire, "Comparative life cycle assessment of lithium-ion batteries for electric vehicles addressing capacity fade," Journal of Cleaner Production, Vol. 229, pp. 787-794, 2019.

[27] Hwanjune Cho, "Uncertainty Management in Prognosis of Electric Vehicle Energy System," Ph.D. Dissertation, Georgia Institute of Technology, 2018.

[28] J.A. Mosquera-Sánchez, M. Sarrazin, K. Janssens, L.P.R. de Oliveira, and W. Desmet, "Multiple target sound quality balance for hybrid electric powertrain noise," Mechanical Systems and Signal Processing, Vol. 99, pp. 478-503, 2018.

[29] F. Ekman, M. Johansson, and J. Sochor, "Creating Appropriate Trust in Automated Vehicle Systems: A Framework for HMI Design," IEEE Transactions on Human-Machine Systems, Vol. 48, No. 1, 2018.

[30] R. Banerjee, M. Mikulski, A. Chakraborty, S. Roy, and P. K. Bose, "ANN meta-model assisted MOPSO application in an EPA-Tier 4 constrained emission-performance trade-off calibration problem of a hydrogen-diesel-EGR dual fuel operation," Fuel, Vol 208, pp. 746$778,2017$.

[31] A. K. Jägerbrand, H. Antonson, "Driving behaviour responses to a moose encounter, automatic speed camera, wildlife warning sign and radio message determined in a factorial simulator study," Accident Analysis and Prevention, Vol. 86, pp. 229-238, 2016.

[32] R. Garcia, J. Gregory, and Fausto Freire, "Dynamic fleet-based lifecycle greenhouse gas assessment of the introduction of electric vehicles in the Portuguese light-duty fleet," The International Journal of Life Cycle Assessment, Vol. 20, No. 9, pp. 1287-1299, 2015.

[33] B. Balta, F. O. Sonmez, and A. Cengiz, "Speed losses in V-ribbed belt drives," Mechanism and Machine Theory, Vol. 86, pp. 1-14, 2015.

[34] A. Noshadravan, L. Cheah, R. Roth, F. Freire, and L. Dias, and J. Gregory, "Stochastic comparative assessment of life-cycle greenhouse gas emissions from conventional and electric vehicles," The International Journal of Life Cycle Assessment, Vol. 20, pp. 854-864, 2015.

[35] J. Vepsalainen, K. Otto, A. Lajunen, and K. Tammi, “Computationally efficient model for energy demand prediction of electric city bus in varying operating conditions," Energy, Vol. 169, pp. 433-443, 2019.

[36] N. Fraikin, K. Funk, M. Frey, and F. Gauterin, "Dimensionality reduction and identification of valid parameter bounds for the efficient calibration of automated driving functions," Automotive and Engine Technology, Vol. 4, pp. 75-91, 2019.

[37] L. Xin, X. Li, Y. Zhu, and M. Liu, "Uncertainty and sensitivity analysis for train ballasted track-bridge system," International Journal of Vehicle Mechanics and Mobility, DOI: 10.1080/00423114.2019.1584678, pp. 1-20, 2019.

[38] D. Silvestre, P. Rosa, J. P. Hespanha, and C. Silvestre, "Sensitivity Analysis for Linear Systems based on Reachability Sets," Conference Proceedings, pp. 1-8, 2019.

[39] Y. Qin, Z. Wang, C. Xiang, M. Dong, C. Hu, and R. Wang, “A novel global sensitivity analysis on the observation accuracy of the coupled vehicle model," International Journal of Vehicle Mechanics and Mobility, DOI: 10.1080/00423114.2018.1517219, pp. 1-23, 2018.

[40] A. Meghoe, R. Loendersloot, and T. Tinga, "Rail wear and remaining life prediction using meta-models," International Journal of Rail Transportation, DOI:10.1080/23248378.2019.1621780, pp.1-27, 2019.

[41] H. Fakhraei, C. T. Driscoll, M. A. Kulp, J. R. Renfro, T. F. Blett, P. F. Brewer, and J. S. Schwartz, "Sensitivity and uncertainty analysis of PnET-BGC to inform the development of Total Maximum Daily Loads (TMDLs) of acidity in the Great Smoky Mountains National Park," Environmental Modelling \& Software, Vol. 95, pp. 156-167, 2017.

[42] S. Zhao, and D. A. Howey, "Global sensitivity analysis of battery equivalent circuit model parameters," IEEE Vehicle Power and
Propulsion Conference (VPPC), DOI: 10.1109/VPPC.2016.7791696, pp. 1-4, 2016.

[43] R. Sala, and N. Baldanzini, and M. Pierini, "Representative surrogate problems as test functions for expensive simulators in multidisciplinary design optimization of vehicle structures," Structural and Multidisciplinary Optimization, Vol. 54, No. 3, pp. 449-468, 2016.

[44] M. H. Shojaeefard, A. Khalkhali, S. Yarmohammadisatri, "An efficient sensitivity analysis method for modified geometry of Macpherson suspension based on Pearson correlation coefficient," International Journal of Vehicle Mechanics and Mobility, DOI: 10.1080/00423114.2017.1283046, pp. 1-27, 2017.

[45] A. Prakash, Rajendra P. Mohanty, "DEA and Monte Carlo simulation approach towards green car selection," Benchmarking: An International Journal, Vol. 24, No. 5, pp.1234-1252, https://doi.org/10.1108/BIJ-11-2015-0112, 2017.

[46] X. Wang, "Modeling and Experiment of Compressed Air Hybrid Engines," University of California, Los Angeles, 2008.

[47] E. Tanaka, "fuel Economy analysis of alternator with kinetic energy storage for a conventional vehicle, SAE International Journal Passenger Cars, Mechanical Systems, Vol. 6, No. 2, 2013.

[48] A. Emadi, K. Rajashekara, S. S. Williamson, "Topological overview of hybrid electric and fuel cell vehicular power system architectures and configurations," IEEE Trans. On Vehicular Technology, Vol. 54, No. 3, 2005 .

[49] S. F. Tie, and C. W. Tan, "A review of energy sources and energy management system in electric vehicles," Renewable and Sustainable Energy Reviews, Vol. 20, pp. 82-102, 2013.

[50] J. Y. Yong, V. K. Ramachandaramurthy, K. M. Tan, and N. Mithulananthan, "A review on the state-of-the-art technologies of electric vehicle,its impacts and prospects," Renewable and Sustainable Energy Reviews, Vol. 49, pp. 365-385, 2015.

[51] M. Mahmoud, R. Garnett, M. Ferguson, and P. Kanaroglou, "Electric buses: A review of alternative powertrains," Renewable and Sustainable Energy Reviews, Vol. 62, pp. 673-684, 2016.

[52] R. Kühne, "Electric buses - An energy efficient urban transportation means," Energy, Vol. 35, No. 12, pp. 4510-4513, 2010.

[53] K. Kivekäs, A. Lajunen, J. Vepsäläinen, and Kari Tammi "City Bus Powertrain Comparison: Driving Cycle Variation and Passenger Load Sensitivity Analysis," energies, Vol. 11, pp. 1-26, 2018.

[54] I. Drovtar, A. Rosin, M. Landsberg, J. Kilter "Large scale electric vehicle integration and its impact on the Estonian power system," In: Proceedings of the IEEE POWERTECH, pp. 1-6, 2013.

[55] Z.Gao,T. LaClair, S. Ou, S. Huff, G. Wu, P. Hao, K. Boriboonsomsin, M. Barth "Evaluation of electric vehicle component performance over eco-driving cycles," Energy, Vol. 173, No, 1, pp. 823-839, 2019.

[56] Z. Darabi, and M. Ferdowsi "Aggregated Impact of Plug-in Hybrid Electric Vehicles on Electricity Demand Profile," IEEE Transactions on Sustainable Energy, Vol. 2, No. 4, 2011.

[57] W. Cai, "Comparison and Review of Electric Machines for Integrated Starter Alternator Applications," Conference Record of the 2004 IEEE Industry Applications Conference, pp. 1-8, 2004.

[58] J. de Santiago, H. Bernhoff, B. Ekergård, S. Eriksson, S. Ferhatovic, R. Waters, and M. Leijon, "Electrical Motor Drivelines in Commercial All-Electric Vehicles: A Review," IEEE Trans. On Vehicular Technology, Vol. 61, No. 2, pp. 475-484, 2012.

[59] H. Budde-Meiwes, J. Drillkens, B. Lunz, J. Muennix, S. Rothgang, J. Kowal, and D. U. Sauer "A review of current automotive battery technology and future prospects," Proceedings of the Institution of Mechanical Engineers, Part D: Journal of Automobile Engineering, Vol. 227, No. 5, pp. 761-776, 2013.

[60] F. V. Conte, "Battery and battery management for hybrid electric vehicles: a review," e \& i Elektrotechnik und Informationstechnik, Vol. 123, No. 10, pp. 424-431, 2006.

[61] Murat Yilmaz, and Philip T. Krein, "Review of Battery Charger Topologies, Charging Power Levels, and Infrastructure for Plug-In Electric and Hybrid Vehicles," IEEE Trans. On Power Electronics, Vol. 28, No. 5, pp. 2151-2169, 2013. 
[62] M. A. Hannan, M. S. H. Lipu, A. Hussain, and A. Mohamed "A review of lithium-ion battery state of charge estimation and management system in electric vehicle applications: Challenges and recommendations," Renewable and Sustainable Energy Reviews, Vol. 78, pp. 834-854, 2017.

[63] G.J. Offer, D.Howey, M. Contestabile, R. Clague, and N.P. Brandon "Comparative analysis of battery electric, hydrogen fuel cell and hybrid vehicles in a future sustainable road transport system," Energy Policy, Vol. 38, pp. 24-29, 2010.

[64] L. Lu, X. Han, J. Li, J. Hua, M. Ouyang "A review on the key issues for lithium-ion battery management in electric vehicles," Journal of Power Sources, Vol. 226, pp. 272-288, 2013.

[65] A. Barré, B. Deguilhem, S. Grolleau, M. Gérard, F Suard, and D. Riu "A review on lithium-ion battery ageing mechanisms and estimationsfor automotive applications," Journal of Power Sources, Vol. 241, pp. 680-689, 2013.

[66] M. A. Hannan, M. M. Hoque A. Mohamed, and A. Ayob "Review of energy storage systems for electric vehicle applications: Issues and challenges," Renewable and Sustainable Energy Reviews, Vol. 69, pp. 771-789, 2017.

[67] G. A. Magallan, C. H. De Angelo, and G. O. García, "Maximization of the Traction Forces in a 2WD Electric Vehicle," IEEE Trans. On Vehicular Technology, Vol. 60, No. 2, pp. 369-380, 2011.

[68] Y. Chen, and J. Wang, "Design and Evaluation on Electric Differentials for Overactuated Electric Ground Vehicles With Four Independent In-Wheel Motors," IEEE Trans. On Vehicular Technology, Vol. 61, No. 4, pp. 1534-1542, 2012.

[69] E. Esmailzadeh, G.R. Vossoughi, and A. Goodarzi, "Dynamic Modeling and Analysis of a Four Motorized Wheels Electric Vehicle," Vehicle System Dynamics, Vol. 53, No. 3, pp. 163-194, 2001.

[70] Y. Chen, and J. Wang, "Design and Experimental Evaluations on Energy

Efficient Control Allocation Methods for Overactuated Electric Vehicles:

Longitudinal Motion Case," IEEE/ASME Trans. On Mechatronics, Vol. 19, No. 2, 2014.

[71] F. Tahami, R. Kazemi, and S. Farhanghi, "A Novel Driver Assist Stability System for All-Wheel-Drive Electric Vehicles," IEEE Trans. On Vehicular Technology, Vol. 52, No. 3, pp. 683-692, 2003.

[72] W. Liu, H. He, and J. Peng "Driving Control Research for Longitudinal Dynamics of ElectricVehicles with Independently Driven Front and Rear Wheels," Mathematical Problems in Engineering, Vol. 2013, No. 408965, pp. 1-17, 2013.

[73] K. Ç. Bayindir, M. A. Gözüküçük, and A. Teke "A comprehensive overview of hybrid electric vehicle: Powertrain configurations, powertrain control techniques and electronic control units," Energy Conversion and Management, Vol. 52, pp. 1305-1313, 2011.

[74] M. A. Karbaschian, and D. Soffker "Review and Comparison of Power Management Approaches for Hybrid Vehicles with Focus on Hydraulic Drives," energies, Vol. 7, pp. 3512-3536, 2014.

[75] M. F. M. Sabri, K. A. Danapalasingam, and M. F. Rahmat "A review on hybrid electric vehicles architecture and energy management strategies," Renewable and Sustainable Energy Reviews, Vol. 53, pp. 1433-1442, 2016.

[76] S. F. Tie, and C. W. Tan "A review of energy sources and energy management system in electric vehicles," Renewable and Sustainable Energy Reviews, Vol. 20, pp.82-102, 2013.

[77] L. Zhang, Y. Fan, R. D. Lorenz, A. Nied, and M. Cheng, "Design and Comparison of Three-Phase and Five-Phase FTFSCW-IPM Motor Open-End Winding Drive Systems for Electric Vehicles Applications," IEEE Trans. On Vehicular Technology, Vol 67, No. 1, pp. 385-396, 2018.

[78] M. Olszewski, "Evaluation of the 2007 Toyota Camry hybrid synergy drive system,” Oak Ridge Nat. Lab., U.S. Dept. Energy, 2009.

[79] D. G. Dorrell, M.-F. Hsieh, M. Popescu, L. Evans, D. A. Staton, and V. Grout, "A review of the design issues and techniques for radial-flux brushless surface and internal rare-earth permanent magnet motors," IEEE Trans. Ind. Electron., Vol. 58, No. 9, 2011.
[80] D. G. Dorrell, A. M. Knight, and M. Popescu, "Performance Improvement in High-Performance Brushless Rare-Earth Magnet Motors for Hybrid Vehicles by Use of High Flux-Density Steel," IEEE Trans. Magnetics, Vol. 47, No. 10, pp. 3016-3609, 2011.

[81] S. Zhu, W. Chen, M. Xie, C. Liu, and K. Wang "Electromagnetic Performance Comparison of Multi-Layered Interior Permanent Magnet Machines for EV Traction Applications," IEEE Trans. On Magnetics, Vol. 54, No. 11, pp. 1-5, 2018.

[82] S. Zhu, Y. Hu, C. Liu, K. Wang, and W. Chen "Reduction of Stator Core Loss in Interior PM Machines for Electric Vehicle Applications," IEEE Trans. On Magnetics, Vol. 54, No. 11, pp. 1-5, 2018.

[83] W. Wang, P. Zheng, M. Wang, Y. Liu, Z. Fu, and Y. Sui "Demagnetization and Permanent-Magnet Minimization Analyses of Less-Rare-Earth Interior Permanent-Magnet Synchronous Machines Used for Electric Vehicles," IEEE Trans. On Magnetics, Vol. 54, No. 11, pp. 1-5, 2018.

[84] Y. Hu, S. Zhu, C. Liu, and K. Wang "Electromagnetic Performance Analysis of Interior PM Machines for Electric Vehicle Applications," IEEE Trans. On Energy Conversion, Vol 33, No. 1, pp. 199-208, 2018.

[85] Y.-H. Hwang, and J. Lee "HEV Motor Comparison of IPMSM With $\mathrm{Nd}$ Sintered Magnet and Heavy Rare-Earth Free Injection Magnet in the Same Size," IEEE Trans. On Applied Superconductivity, Vol. 28 , No. 3, pp. 1-5, 2018.

[86] S. Zhu, Y. Hu, C. Liu, and K. Wang "Iron Loss and Efficiency Analysis of Interior PM Machines for Electric Vehicle Applications," IEEE Trans. On Industrial Electronics, Vol. 65, No. 1, pp. 114-124, 2018.

[87] J. B. Wang, X. Yuan, and K. Atallah, "Design optimization of a surface mounted permanent-magnet motor with concentrated windings for electric vehicle applications," IEEE Trans. Vehicular Technology, Vol. 62, No. 3, pp. 1053-1064, 2013.

[88] A. Wang, Y. Jia, and W. Soong, "Comparison of five topologies for an interior permanent-magnet machine for a hybrid electric vehicle," IEEE

Trans. Magnetics, Vol. 47, No. 10, pp. 3606-3609, 2011.

[89] Y.-P. Yang, and M.-T. Peng, "A Surface-Mounted Permanent-Magnet Motor With Sinusoidal Pulsewidth-Modulation-Shaped Magnets," IEEE

Trans. Magnetics, Vol. 55, No. 1, pp. 1-8, 2019

[90] H.-K. Yeo, H.-J. Park, J.-N. Seo, S.-Y. Jung, J.-S. Ro, and H.-K. Jung, "Electromagnetic and Thermal Analysis of a Surface-Mounted Permanent-Magnet Motor with Overhang Structure," IEEE Trans. Magnetics, Vol. 53, No. 6, pp. 1-4, 2017.

[91] N. P. Shah, A. D. Hirzel, and B. Cho, "Transmissionless Selectively Aligned Surface-Permanent-Magnet BLDC Motor in Hybrid Electric Vehicles," IEEE Trans. Industrial Electronics, Vol. 57, No. 2, pp. 19, 2010.

[92] J. Fan, C. Zhang, Z. Wang, Y. Dong, C. E. Nino, A. R. Tariq, and E. G. Strangas, "Thermal Analysis of Permanent Magnet Motor for the Electric Vehicle Application Considering Driving Duty Cycle," IEEE Trans. Magnetics, Vol. 46, No. 6, pp. 1-4, 2010.

[93] S. Wu, L. Song, and S. Cui, "Study on Improving the Performance of Permanent Magnet Wheel Motor for the Electric Vehicle Application," IEEE Trans. Magnetics, Vol. 43, No. 1, pp. 438-442, 2007.

[94] C. Tong, M. Wang, P. Zheng, J. Bai, and J. Liu "Characteristic Analysis and Functional Validation of a Brushless Flux-Modulated Double-Rotor Machine for HEVs," IEEE Trans. On Industrial Electronics, Vol. 66, No. 1, pp. 663-673, 2019.

[95] Y. Gao, D. Li, R. Qu, H. Ding, and W. Kong "A Novel Double Stator Flux Modulation Machine With Low-Temperature Superconducting Windings," IEEE Trans. On Applied Superconductivity, Vol. 28, No. 3, pp. 1-6, 2018.

[96] C. Yunyun, Q. Li, Z. Xiaoyong, W. Hua, and Z. Wang "Electromagnetic Performance Analysis of Double-Rotor Stator Permanent Magnet Motor for Hybrid Electric Vehicle," IEEE Trans. On Magnetics, Vol. 48, No. 11, pp. 4204-4207, 2012.

[97] Z. Xiang, X. Zhu, L. Quan, and Y. Chen "Design and Analysis of Double-Air-Gap Flux-Modulated Permanent Magnet Motor 
Considering Leading Working Harmonics," IEEE Trans. On Magnetics, Vol. 55, No. 6, pp. 1-5, 2019.

[98] H. Zhao, C. Liu, Z. Song, and S. Liu "A Consequent-Pole PM Magnetic-Geared Double-Rotor Machine With Flux-Weakening Ability for Hybrid Electric Vehicle Application," IEEE Trans. On Magnetics, Vol. 55, No. 7, pp. 1-7, 2019.

[99] M. Wang, C. Tong, Z. Song, J. Liu, and P. Zheng "Performance Analysis of an Axial Magnetic-Field-Modulated Brushless DoubleRotor Machine for Hybrid Electric Vehicles," IEEE Trans. On Industrial Electronics, Vol. 66, No. 1, pp. 806-817, 2019.

[100] J. Bai, J. Liu, P. Zheng, and C. Tong "Design and Analysis of a Magnetic-Field Modulated Brushless Double-Rotor Machine-Part II: Winding Configuration," IEEE Trans. On Industrial Electronics, Vol. 66, No. 4, pp. 2550-2560, 2019.

[101]J. Druant, H. Vansompel, F. De Belie, J. Melkebeek, P. Sergeant, "Torque Analysis on a Double Rotor Electrical Variable Transmission With Hybrid Excitation," IEEE Trans. On Industrial Electronics, Vol. 64, No. 1, pp. 60-68, 2017.

[102]C. Feng, X. Jing, G. Bin, C. Shukang, and Z. Jiange "Double-Stator Permanent Magnet Synchronous in-Wheel Motor for Hybrid Electric Drive System," IEEE Trans. On Magnetics, Vol. 45, No. 1, pp. 278$281,2009$.

[103]L. Zhou and W. Hua "Influences of Stator Teeth Number on PM Coupling

Levels of Co-Axial Dual-Mechanical-Port Flux-Switching PM Machines," IEEE Trans. On Magnetics, Vol. 55, No. 7, pp. 1-7, 2019.

[104]H. Torkaman, A. Ghaheri, and A. Keyhani "Design of Rotor Excited Axial Flux-Switching Permanent Magnet Machine," IEEE Trans. On Energy Conversion, Vol. 33, No. 3, pp. 1175-1183, 2018.

[105]P. Su, W. Hua, and Z. Wu, "Analysis of the operation principle for rotor permanent-magnet flux-switching machines," IEEE Trans. On Industry Electronics, Vol. 65, No. 2, pp. 1062-1073, 2018.

[106]X. Zhu, Z. Shu, L. Quan, Z. Xiang, and X. Pan, "Design and multicondition comparison of two outer-rotor flux-switching permanent magnet motors for in-wheel traction applications," IEEE Trans. On Industry Electronics, Vol. 64, No. 8, pp. 6137-6148, Aug. 2017.

[107]N. Ahmad, F. Khan, H. Ali, S. Ishaq, E. Sulaiman, "Outer rotor wound field flux switching machine for In-wheel direct drive application," IET Electric Power Applications, Vol. 13, No. 6, pp. 757-765, 2019.

[108]L. Mo, X. Zhu, T. Zhang, L. Quan, Q. Lu, and X. Bai "Loss and Efficiency of a Flux-Switching Permanent-Magnet Double-Rotor Machine With High Torque Density," IEEE Trans. On Magnetics, Vol. 54, No. 11, pp. 1-5, 2018.

[109]L. Mo, T. Zhang, and Q. Lu "Thermal Analysis of a Flux-Switching Permanent-Magnet Double-Rotor Machine With a 3-D Thermal Network Model," IEEE Trans. On Applied Superconductivity, Vol. 29, No. 2, pp. 1-5, 2019.

[110]L. Mo, T. Zhang, and Q. Lu "Design and Analysis of an Outer-RotorPermanent-Magnet Flux-Switching Machine for Electric Vehicle Applications," IEEE Trans. On Applied Superconductivity, Vol. 29, No. 2, pp. 1-5, 2019.

[111]W. Zhang, X. Liang, and F. Yu "Fault-Tolerant Control of Hybrid Excitation Axial Field Flux-Switching Permanent Magnet Machines," IEEE Trans. On Magnetics, Vol. 54, No. 11, pp. 1-5, 2018.

[112]S. Li, S. Zhang, T. G. Habetler, and R. G. Harley "Modeling, Design Optimization, and Applications of Switched Reluctance MachinesA Review," IEEE Trans. On Industry Applications, Vol. 55, No. 3, pp. 2660-2681, 2019.

[113]M. Kawa, K. Kiyota, J. Furqani, and A. Chiba "Acoustic Noise Reduction of a High-Efficiency Switched Reluctance Motor for Hybrid Electric Vehicles With Novel Current Waveform," IEEE Trans. On Industry Applications, Vol. 55, No. 3, pp. 2519-2528, 2019.

[114]X. Sun, K. Diao, G. Lei, Y. Guo, and J. Zhu "Acoustic Noise Reduction of a High-Efficiency Switched Reluctance Motor for Hybrid Electric Vehicles With Novel Current Waveform," IEEE Trans. On Vehicular Technology, Vol. 68, No. 6, pp. 5537-5547, 2019.

[115]Z. Xu, J. Liu, M.-Ji Kim, D.-H. Lee, and J.-W. Ahn, "Characteristics Analysis and Comparison of Conventional and Segmental Rotor Type
12/8 Switched Reluctance Motors," IEEE Trans. On Industry Applications, Vol. 55, No. 3, pp. 3129-3137, 2019.

[116]J. Zhu, K. W. E. Cheng, X. Xue, and Y. Zou, "Design of a New Enhanced Torque In-Wheel Switched Reluctance Motor With Divided Teeth for Electric Vehicles," IEEE Trans. On Magnetics, Vol 53, No. 11, pp. 1-4, 2017.

[117]S. P. Nikam, V. Rallabandi, and B. G. Fernandes, "A High-TorqueDensity Permanent-Magnet Free Motor for in-Wheel Electric Vehicle Application," IEEE Trans. On Industry Applications, Vol. 48, No. 6 , pp. 2287-2295, 2012.

[118]X. D. Xue, K. W. E. Cheng, T.W. Ng, and N. C. Cheung, "MultiObjective Optimization Design of In-Wheel Switched Reluctance Motors in Electric Vehicles," IEEE Trans. On Industry Applications, Vol. 57, No. 9, pp. 2980-2987, 2010.

[119]K. Kiyota, S. Nakano, and A. Chiba "A Fast Calculation Method of Optimal Ratio of Outer Diameter and Axial Length for Torque Improvement in Switched Reluctance Motor," IEEE Trans. On Industry Applications, Vol. 54, No. 6, pp. 5802-5811, 2018.

[120]C. Gan, J. Wu, Q. Sun, W. Kong, H. Li, and Y. Hu, "A Review on Machine Topologies and Control Techniques for Low-Noise Switched Reluctance Motors in Electric Vehicle Applications," IEEE Access, Vol. 6, 2018.

[121]D. G. Dorrell, "Combined thermal and electromagnetic analysis of permanent magnet and induction machines to aid calculation," IEEE Trans. On Industry Electronics, Vol. 55, No. 10, pp. 3566-3574, Oct. 2008.

[122]L. D. Marlino, "Report on Toyota Prius motor thermal management," Oak Ridge Nat. Lab., U.S. Dept. Energy, Oak Ridge, TN, 2005.

[123]J. de Santiago, H. Bernhoff, B. Ekergård, S. Eriksson, S. Ferhatovic, R. Waters, and M. Leijon, "Electrical Motor Drivelines in Commercial All-Electric Vehicles: A Review," IEEE Trans. On Vehicular Technology, Vol. 61, No. 2, pp. 475-484, 2012.

[124]Z. Yang, Fei Shang, Ian P. Brown, and Mahesh Krishnamurthy, "Comparative Study of Interior Permanent Magnet, Induction, and Switched Reluctance Motor Drives for EV and HEV Applications," IEEE Trans. On Transportation Electrification, Vol. 1, No. 3, pp. 245$254,2015$.

[125]D. G. Dorrell, A. M. Knight, L. Evans, and M. Popescu, "Analysis and Design Techniques Applied to Hybrid Vehicle Drive MachinesAssessment of Alternative IPM and Induction Motor Topologies," IEEE Trans. On Industrial Electronics, Vol. 59, No. 10, pp. 3690$3699,2012$.

[126]G. Pellegrino, Al. Vagati, B. Boazzo, and P. Guglielmi, "Comparison of Induction and PM Synchronous Motor Drives for EV Application Including Design Examples," IEEE Trans. On Industrial Applications, Vol. 48, No. 6, pp. 2322-2332, 2012.

[127]M. Popescu, J. Goss, D. A. Staton, D. Hawkins, Y. C. Chong, and A. Boglietti, "Electrical Vehicles-Practical Solutions for Power Traction Motor Systems," IEEE Trans. On Industrial Applications, Vol. 54, No. 3, pp. 2751-2762, 2018.

[128]W.-Y. Ji, G. Jeong, C.-B. Park, I-H. Jo, and H.-W. Lee, "A Study of Non-Symmetric Double-Sided Linear Induction Motor for Hyperloop All-In-One System (Propulsion, Levitation, and Guidance)," IEEE Trans. On Magnetics, Vol. 54, No. 11, pp.1-4, 2018.

[129] S.-M. Jang, Y.-S. Park, S.-Y. Sung, K.-Bok Lee, H.-W. Cho, and D.Joon You, "Dynamic Characteristics of a Linear Induction Motor for Predicting Operating Performance of Magnetic Levitation Vehicles Based on Electromagnetic Field Theory," IEEE Trans. On Magnetics, Vol. 47, No. 10, pp.3673-3676, 2011.

[130]J. Lim, J.-H. Jeong, C.-H. Kim, C.-W. Ha, and D.-Y. Park, “Analysis and Experimental Evaluation of Normal Force of Linear Induction Motor for Maglev Vehicle," IEEE Trans. On Magnetics, Vol. 53, No. 11, pp.1-4, 2017.

[131]T. Wang, B. Li, B. Xie, and F. Fang, "Linear Induction Motors for Driving Vehicles Climbing on Steel Plates," IEEE Trans. On Energy Conversion, Vol. 29, No. 3, pp.788-789, 2014. 
[132]Y. K. Choi, H. S. Yoon, and C. S. Koh, "Pole-Shape Optimization of a Switched-Reluctance Motor for Torque Ripple Reduction," IEEE Trans. On Magnetics, Vol. 43, No. 4, pp.1797-1800, 2007.

[133]D.-H. Lee, T. H. Pham, and J.-W. Ahn, "Design and Operation Characteristics of Four-Two Pole High-Speed SRM for Torque Ripple Reduction," IEEE Trans. On Industrial Electronics, Vol. 60, No. 9, pp.3637-3643, 2013.

[134]M. S. Islam, and I. Husain, "Torque-Ripple Minimization with Indirect Position and Speed Sensing for Switched Reluctance Motors," IEEE Trans. On Industrial Electronics, Vol. 47, No. 5, pp.1126-1133, 2000.

[135]F. S, ahin, H. B. Ertan, and K. Leblebicioglu, "Optimum Geometry for Torque Ripple Minimization of Switched Reluctance Motors," IEEE Trans. On Energy Conversion, Vol. 15, No. 1, pp.30-39, 2000.

[136]H. Li, B. Bilgin, and A. Emadi, "An Improved Torque Sharing Function for Torque Ripple Reduction in Switched Reluctance Machines," IEEE Trans. On Power Electronics, Vol. 34, No. 2, pp.1635-1644, 2019.

[137]P. K. Reddy, D. Ronanki and P. Parthiban, "Direct torque and flux control of switched reluctance motor with enhanced torque per ampere ratio and torque ripple reduction," Electronics Letters, Vol. 55, No. 8, pp.477-478, 2019.

[138]J. Ye, B. Bilgin, and A. Emadi, "An Offline Torque Sharing Function for Torque Ripple Reduction in Switched Reluctance Motor Drives," IEEE Trans. On Energy Conversion, Vol. 30, No. 2, pp. 726-735, 2015.

[139]X. Cao, J. Zhou, C. Liu, and Z. Deng, “Advanced Control Method for a Single-Winding Bearingless Switched Reluctance Motor to Reduce Torque Ripple and Radial Displacement," IEEE Trans. On Energy Conversion, Vol. 32, No. 4, pp. 1533-1543, 2015.

[140]X. Deng, B. Mecrow, H. Wu, and R. Martin, "Design and Development of Low Torque Ripple Variable-Speed Drive System With Six-Phase Switched Reluctance Motors," IEEE Trans. On Energy Conversion, Vol. 33, No. 1, pp. 420-429, 2018.

[141]X. Deng, B. Mecrow, H. Wu, and R. Martin, "Design and Development of Low Torque Ripple Variable-Speed Drive System With Six-Phase Switched Reluctance Motors," Canadian Journal of Electrical and Computer Engineering, Vol. 38, No. 4, pp. 318-322, 2015.

[142]T. Arakawa, M. Takemoto, S. Ogasawara, K. Inoue, O. Ozaki, H. Hojo, and H. Mitani, "Examination of an Interior Permanent Magnet Type Axial Gap Motor for the Hybrid Electric Vehicle," IEEE Trans. On Magnetics, Vol. 47, No. 10, pp. 3602-3605, 2011.

[143]S. Zhu, Y. Hu, C. Liu, and K. Wang, "Iron Loss and Efficiency Analysis of Interior PM Machines for Electric Vehicle Applications," IEEE Trans. On Industrial Electronics, Vol. 65, No. 1, pp. 114-124, 2018.

[144]W. Jiang, S. Feng, Z. Zhang, J. Zhang, and Z. Zhang, "Study of Efficiency Characteristics of Interior Permanent Magnet Synchronous Motors," IEEE Trans. On Magnetics, Vol. 54, No. 11, pp. 1-5, 2018.

[145]R. Yang, N. Schofield, and A. Emadi, "Comparative Study Between Interior and Surface Permanent Magnet Traction Machine Designs," IEEE Transportation Electrification Conference and Expo (ITEC), DOI: 10.1109/ITEC.2016.7520249, pp. 1-6, 2016.

[146]P.Asef, R. Bargallo Perpina, and M. R. Barzegaran, "Global sizing optimisation using dual-level response surface method based on mixed-resolution central composite design for permanent magnet synchronous generators," IET Electric Power Applications, Vol. 12, No. 5, pp. 684- 692, 2018.

[147]P.Asef, R. Bargallo Perpina, M. R. Barzegaran, A. Lapthorn, and D. Mewes "Multiobjective Design Optimization Using Dual-Level Response Surface Methodology and Booth's Algorithm for Permanent Magnet Synchronous Generators," IEEE Trans. On Energy Conversion, Vol. 33, No. 2, pp. 652-659, 2018.

[148]D. Zarko, D. Ban, and T. A. Lipo "Analytical Solution for Electromagnetic Torque in Surface Permanent-Magnet Motors Using Conformal Mapping," IEEE Trans. On Magnetics, Vol. 45, No. 7, pp. 2943-2954, 2009.
[149]M. Hafner, D. Franck, and K. Hameyer "Static Electromagnetic Field Computation by Conformal Mapping in Permanent Magnet Synchronous Machines," IEEE Trans. On Magnetics, Vol. 46, No. 8, pp. 3105-3108, 2010.

[150]B.-H. Lee, J.-P. Hong, and J.-H. Lee “Optimum Design Criteria for Maximum Torque and Efficiency of a Line-Start Permanent-Magnet Motor Using Response Surface Methodology and Finite Element Method," IEEE Trans. On Magnetics, Vol. 48, No. 2, pp. 863-866, 2012.

[151]K. Abbaszadeh and F. R. Alam "On-Load Field Component Separation in Surface-Mounted Permanent-Magnet Motors Using an Improved Conformal Mapping Method," IEEE Trans. On Magnetics, Vol. 52, No. 2, pp. 1-12, 2016.

[152]A. Hanic, D. Zarko, and Z. Hanic "A Novel Method for No-Load Magnetic Field Analysis of Saturated Surface Permanent-Magnet Machines Using Conformal Mapping and Magnetic Equivalent Circuits," IEEE Trans. On Energy Conversion, Vol. 31, No. 2, pp. 740-749, 2016.

[153]R. Liu, H. Zhao, C. Tong, G. Chen, P. Zheng, and G. Gu "Experimental Evaluation of a Radial-Radial-Flux CompoundStructure Permanent-Magnet Synchronous Machine Used for HEVs," IEEE Trans. On Magnetic, Vol. 45, No. 1, pp. 645-649, 2009.

[154]C-T. Liu, H.-Y. Chung, and C.-C. Hwang "Design Assessments of a Magnetic-Geared Double-Rotor Permanent Magnet Generator," IEEE Trans. On Magnetic, Vol. 50, No. 1, pp. 1-4, 2014.

[155]Z. Zong, L. Quan, Z. Xiang "Comparison of Double-Stator FluxSwitching Permanent Magnet Machine and Double-Stator Permanent Magnet Synchronous Machine for Electric Vehicle Applications," IEEE 17th International Conference on Electrical Machines and Systems, pp. 1-6, 2014.

[156]D. Kim, H. Hwang, S. Bae, and C. Lee "Analysis and Design of a Double-Stator Flux-Switching Permanent Magnet Machine Using Ferrite Magnet in Hybrid Electric Vehicles," IEEE Trans. On Magnetic, Vol. 52, No. 7, pp. 1-4, 2016.

[157]C. C. Awah, and Z. Q. Zhu "Comparative Study of High Performance Double-Stator Switched Flux Permanent Magnet Machines," IEEE Vehicle Power and Propulsion Conference (VPPC), DOI: 10.1109/VPPC.2016.7791632, pp. 1-6, 2016.

[158]S. Wang, W. Zhao, and M. Kang "Design and Analysis of DoubleSided Linear Primary Permanent Magnet Vernier Motor," 19th International Conference on Electrical Machines and Systems (ICEMS), pp. 1-5, 2016.

[159]Y. Jiang, J. Zhang, and T. Li “A Permanent Magnet Brushless Doubly Fed Generator With Segmented Structure," IEEE Trans. On Magnetic, Vol. 54, No. 3, pp. 1-4, 2018.

[160]Y. Jiang, J. Zhang, and T. Li "Loss and Efficiency of a Flux-Switching Permanent-Magnet Double-Rotor Machine With High Torque Density," IEEE Trans. On Magnetic, Vol. 54, No. 11, pp. 1-5, 2018.

[161]Gun H. Jang, and S. J. Park "Characterization of a Single-Phase Induction Motor Due to the Effect of Slot Opening," IEEE Trans. On Magnetic, Vol. 40, No. 4, pp. 2065-2067, 2004.

[162] Y. Kawase, T. Yamaguchi, Z. Tu, N. Toida, N. Minoshima, and K. Hashimoto "Effects of Skew Angle of Rotor in Squirrel-Cage Induction Motor on Torque and Loss Characteristics," IEEE Trans. On Magnetic, Vol. 45, No. 3, pp. 1700-1703, 2009.

[163]G. Lee, S. Min, and J-P. Hong "Optimal Shape Design of Rotor Slot in Squirrel-Cage Induction Motor Considering Torque Characteristics," IEEE Trans. On Magnetic, Vol. 49, No. 5, pp. $2197-$ 2200, 2013.

[164]P. S. Andersen, D. G. Dorrell, N. C. Weihrauch, and P. E. Hansen "Synchronous Torques in Split-Phase Induction Motors," IEEE Trans. On Industry Applications, Vol. 46, No. 1, pp. 222-231, 2010.

[165]R. Gunabalan, P. Sanjeevikumar, F. Blaabjerg, O. Ojo, and V. Subbiah, "Synchronous Torques in Split-Phase Induction Motors," IEEE Trans. On Power Electronics, Vol. 30, No. 12, pp. 6472-6475, 2015.

[166]D. Zhang, C. S. Park, and C. S. Koh “A New Optimal Design Method of Rotor Slot of Three-Phase Squirrel Cage Induction Motor for 
NEMA Class D Speed-Torque Characteristic Using Multi-Objective Optimization Algorithm," IEEE Trans. On Magnetic, Vol. 48, No. 2, pp. 879-882, 2012.

[167]B. Liu, R. Badcock, H. Shu, L. Tan, and J. Fang "Electromagnetic Characteristic Analysis and Optimization Design of a Novel HTS Coreless Induction Motor For High-Speed Operation," IEEE Trans. On Applied Superconductivity, Vol. 28, No. 4, pp. 1-5, 2018.

[168]K. Yamazaki, A. Suzuki, M. Ohto, T. Takakura, and S. Nakagawa "Equivalent Circuit Modeling of Induction Motors Considering Stray Load Loss and Harmonic Torques Using Finite Element Method," IEEE Trans. On Magnetic, Vol. 47, No. 5, pp. 986-989, 2011.

[169] T. Marcic, B. Stumberger, G. Stumberger, M. Hadziselimovic, and P. D. Dolinar "Line-Starting Three- and Single-Phase Interior Permanent Magnet Synchronous Motors-Direct Comparison to Induction Motors," IEEE Trans. On Magnetic, Vol. 44, No. 11, pp. 4413-4416, 2008.

[170]A. Stermecki, I. Ticar, I. Zagradisnik, and P. Kitak "Line-Starting Three- and Single-Phase Interior Permanent Magnet Synchronous Motors-Direct Comparison to Induction Motors," IEEE Trans. On Magnetic, Vol. 44, No. 11, pp. 4413-4416, 2008.

[171]M. Takeno, A. Chiba, N. Hoshi, S. Ogasawara, M. Takemoto, M. A. Rahman "Test Results and Torque Improvement of the $50-\mathrm{kW}$ Switched Reluctance Motor Designed for Hybrid Electric Vehicles," IEEE Trans. On Industry Applications, Vol. 48, No. 4, pp. 1327-1334, 2012.

[172]M. Takeno, A. Chiba, N. Hoshi, S. Ogasawara, M. Takemoto, M. A. Rahman "Online and Offline Rotary Regression Analysis of Torque Estimator for Switched Reluctance Motor Drives," IEEE Trans. On Energy Conversion, Vol. 22, No. 4, pp. 810-818, 2007.

[173]C. Moron, A.Garcia , E. Tremps, and J. A. Somolinos "Torque Control of Switched Reluctance Motors," IEEE Trans. On Magnetics, Vol. 48, No. 4, pp. 1661-1664, 2012.

[174]J. Ye, B. Bilgin, and A. Emadi "An Offline Torque Sharing Function for Torque Ripple Reduction in Switched Reluctance Motor Drives," IEEE Trans. On Energy Conversion, Vol. 30, No. 2, pp. 726-735, 2015.

[175]M. A. Raj and A. Kavitha "Effect of Rotor Geometry on Peak and Average Torque of External-Rotor Synchronous Reluctance Motor in Comparison With Switched Reluctance Motor for Low-Speed DirectDrive Domestic Application," IEEE Trans. On Magnetics, Vol. 53, No. 11, pp. 1-8, 2017.

[176]K. Lu, U. Jakobsen, and P. O. Rasmussen "Single-Phase Hybrid Switched Reluctance Motor for Low-Power Low-Cost Applications," IEEE Trans. On Magnetics, Vol. 47, No. 10, pp. 3288-3291, 2011.

[177]M. J. Kermanipour and B. Ganji "Modification in Geometric Structure of

Double-Sided Axial Flux Switched Reluctance Motor for Mitigating Torque Ripple," Canadian Journal of Electrical and Computer Engineering, Vol. 38, No. 4, pp. 318-322, 2015.

[178]C. Choi, D. Lee, and K. Park "Fuzzy Design of a Switched Reluctance Motor Based on the Torque Profile Optimization," IEEE Trans. On Magnetics, Vol. 36, No. 5, pp. 3548-3550, 2000.

[179]N. K. Sheth, and K. R. Rajagopal, "Torque Profiles of a Switched Reluctance Motor Having Special Pole Face Shapes and Asymmetric Stator Poles," IEEE Trans. On Magnetics, Vol. 40, No. 4, pp. 20352037, 2004.

[180]N. K. Sheth, and K. R. Rajagopal, "Optimum Pole Arcs for a Switched Reluctance Motor for Higher Torque With Reduced Ripple," IEEE Trans. On Magnetics, Vol. 39, No. 5, pp. 3214-3216, 2003.

[181]N. K. Sheth, and K. R. Rajagopal, "Variations in Overall Developed Torque of a Switched Reluctance Motor With Airgap Nonuniformity," IEEE Trans. On Magnetics, Vol. 41, No. 10, pp. 3973-3975, 2005.

[182]N. K. Sheth, and K. R. Rajagopal, "Effects of Nonuniform Airgap on the Torque Characteristics of a Switched Reluctance Motor," IEEE Trans. On Magnetics, Vol. 40, No. 4, pp. 2032-2034, 2004.

[183] Y. K. Choi, H. S. Yoon, and C. S. Koh, "Pole-Shape Optimization of a Switched-Reluctance Motor for Torque Ripple Reduction," IEEE Trans. On Magnetics, Vol. 43, No. 4, pp. 1797-1800, 2007.
[184]X. D. Xue, K. W. E. Cheng, S. L. Ho, and K. F. Kwok, "TrigonometryBased Numerical Method to Compute Nonlinear Magnetic Characteristics in Switched Reluctance Motors," IEEE Trans. On Magnetics, Vol. 43, No. 4, pp. 1845-1848, 2007.

[185]D. G. Dorrell, I. Chindurza, and C. Cossar, "Effects of Rotor Eccentricity on Torque in Switched Reluctance Machines," IEEE Trans. On Magnetics, Vol. 41, No. 10, pp. 3961-3963, 2005.

[186]T. Sebastian, "Temperature Effects on Torque Production and Efficiency of PM Motors Using NdFeB Magnets," IEEE Trans. On Industry Applications, Vol. 31, No. 2, pp. 353-357, 1995.

[187] V. Ghorbanian, S. Hussain, S. Hamidizadeh, R. Chromik, and D. Lowther, "The Role of Temperature-Dependent Material Properties in Optimizing the Design of Permanent Magnet Motors," IEEE Trans. On Magnetics, Vol. 54, No. 3, pp. 1-4, 2018.

[188]A. Hanif, A. I. Bhatti, and Q. Ahmed, "Managing Thermally Derated Torque of an Electrified Powertrain Through LPV Control," IEEE/ASME Trans. On Mechatronics, Vol. 23, No. 1, pp. 364-376, 2018.

[189]D. Fernandez, D. Hyun, Y. Park, D. D. Reigosa, S. B. Lee, D-M. Lee, and F. Briz, "Permanent Magnet Temperature Estimation in PM Synchronous Motors Using Low-Cost Hall Effect Sensors," IEEE Trans. On Industry Applications, Vol. 53, No. 5, pp. 4515-4525, 2017.

[190]S. Li, B. Sarlioglu, S. Jurkovic, N. R. Patel, and P. Savagian, "Comparative Analysis of Torque Compensation Control Algorithms of Interior Permanent Magnet Machines for Automotive Applications Considering the Effects of Temperature Variation," IEEE Trans. On Transportation Electrification, Vol. 3, No. 3, pp. 668-681, 2017.

[191]K-H. Seong, J. Hwang, J. Shim, and H-W. Cho, "Investigation of Temperature Rise in an Induction Motor Considering the Effect of Loading," IEEE Trans. On Magnetics, Vol. 50, No. 11, pp. 1-4, 2014.

[192]K. Bennion and J. Cousineau "Sensitivity Analysis of Traction Drive Motor Cooling," IEEE Transportation Electrification Conference and Expo (ITEC), Vol. 65, No.7, pp. 1-6, 2012.

[193]P. Li, W. Ding, and G. Liu, "Sensitivity Analysis and Design of a High Performance Permanent-Magnet-Assisted Synchronous Reluctance Motor for EV Application," IEEE Transportation Electrification Conference and Expo (ITEC), pp. 1-6, 2018.

[194]L. Lai and M. Ehsani "Sensitivity Analysis of Vehicle Performance to Transmission Parameters in Parallel HEVs with Dynamic Programming Optimization," IEEE Transportation Electrification Conference and Expo (ITEC), pp. 1-5, 2012.

[195]E. Sulaiman, and T. Kosaka, "Parameter Sensitivity Study for Optimization of Field-Excitation Flux Switching Synchronous Machine for Hybrid Electric Vehicles," 7th IEEE Conference on Industrial Electronics and Applications (ICIEA), pp. 1-6, 2012.

[196]Z. Yueying, Y. Chuantian, Y. Yuan, W. Weiyan, Z. Chengwen, "Design and optimisation of an In-wheel switched reluctance motor for electric vehicles," IET Intelligent Transport Systems, Vol. 13, No.1, pp. 175-182, 2018.

[197]A. M. Omekanda, "Robust Torque and Torque-per-Inertia Optimization of a Switched Reluctance Motor Using the Taguchi Methods," IEEE Trans. On Industry Applications, Vol. 42, No.2, pp. 473-478, 2006.

[198]G. Krebs, E. de Cecco, C. Marchand, "Design approach of an axial flux motor for electrical powertrain vehicle," IEEE XXth International Conference on Electrical Machines, pp. 1-6, 2012.

[199]Z. Xiang, X. Zhu, Li Quan, Y. Du, C. Zhang, and D. Fan, "Multilevel Design Optimization and Operation of a Brushless Double Mechanical Port Flux-Switching Permanent-Magnet Motor," IEEE Trans. On Industrial Electronics, Vol. 63, No.10, pp. 6042-6054, 2016.

[200]Y-P. Yang, and D. S. Chuang, "Optimal Design and Control of a Wheel Motor for Electric Passenger Cars," IEEE Trans. On Magnetics, Vol. 43, No.1, pp. 51-61, 2007.

[201]X. Zhu, Z. Xiang, L. Quan, W. Wu, and Y. Du "Multimode Optimization Design Methodology for a Flux-Controllable Stator Permanent Magnet Memory Motor Considering Driving Cycles," IEEE Trans. On Industrial Electronics, Vol. 65, No.7, pp. 5353-5366, 2018. 
[202]X. Zhu, Z. Shu, L. Quan, Z. Xiang, and X. Pan, "Design and Multicondition Comparison of Two Outer-Rotor Flux-Switching Permanent-Magnet Motors for In-Wheel Traction Applications," IEEE Trans. On Industrial Electronics, Vol. 64, No.8, pp. 6137-6148, 2017.

[203]X. Zhu, J. Huang, L. Quan, Z. Xiang, and B. Shi, “Comprehensive Sensitivity Analysis and Multiobjective Optimization Research of Permanent Magnet Flux-Intensifying Motors," IEEE Trans. On Industrial Electronics, Vol. 66, No.4, pp. 2613-2626, 2019.

[204]O. Sundström, L. Guzzella, and P. Soltic, "Torque-Assist Hybrid Electric Powertrain Sizing: From Optimal Control Towards a Sizing Law," IEEE Trans. On Control systems Technology, Vol. 18, No.4, pp. 837-849, 2010.

[205]T. Nakada, S. Ishikawa, and S. Oki, "Development of an Electric Motor for a Newly Developed Electric Vehicle," SAE, doi:10.4271/2014-01-1879, pp. 1-7, 2014.

[206]K. Ramakrishnan, M. Gobbi, and G. Mastinu, "Multi-Objective Optimization of In-Wheel Motor Powertrain and Validation Using Vehicle Simulator," Tenth Inter. Conf. on Ecological Vehicles and Renewable Energies, pp. 1-9, 2015.

[207]J. M. Lujan, C. Guardiola, B. Pla and A. Reig, "Cost of ownershipefficient hybrid electric vehicle powertrain sizing for multi-scenario driving cycles," Journal of Automobile Engineering, Vol. 230, No. 3, pp. 1-13, 2016.

[208]Y-y. Wang, and F-n. Yang, "SRM Representative Parameters Effect on In-wheel Motored Vehicle Performance," IEEE International Conference on Intelligent Transportation Engineering, pp.1-6, 2017.

[209]T. Nakada, S. Ishikawa, and S. Oki, "Development of an Electric Motor for a Newly Developed Electric Vehicle," SAE, doi:10.4271/2014-01-1879, pp. 1-7, 2014.

[210]A. Saltelli, and P. Annoni "How to avoid a perfunctory sensitivity analysis," Environmental Modelling \& Software, Vol. 25, pp. 1508$1517,2010$.

[211]E. Borgonovoa, and E. Plischke "Sensitivity analysis: A review of recent advances," European Journal of Operational Research, Vol. 248, pp. 869-887, 2016.

[212]A. Saltelli, K. Aleksankina, W. Beckerd, P. Fennell, F. Ferretti, N. Holst, S. Lig, and Q. Wu "Why so many published sensitivity analyses are false: A systematic review of sensitivity analysis practices," Environmental Modelling \& Software, Vol. 114, pp.29-39, 2019.

[213]B. Iooss, and P. Lemaître "Uncertainty Management in SimulationOptimization of Complex Systems, Operations Research/Computer Science Interfaces Series," Springer Text book, Chapter 5, DOI 10.1007/978-1-4899-7547-8_5, 2015.

[214]E. Leamer, "Let's take the con out of econometrics, and Sensitivity analysis would help," Modelling Economic Series. Clarendon Press, Oxford, Vol. 73, No. 1, pp. 31-43, 1990.

[215]J. Coggan, T. Bartol, E. Esquenazi, J. Stiles, S. Lamont, M. Martone, D. Berg, M. Ellisman, and T. Sejnowski "Evidence for ectopic neurotransmission at a neuronal synapse," Science Vol. 309, pp.446$451,2005$.

[216]J. C. Helton, and F. J. Davis "Latin hypercube sampling and the propagation of uncertainty in analyses of complex systems," Reliability Engineering \& System Safety, Vol.81(1), pp. 23-69, 2003.

[217]M. D. McKay, R. J. Beckman, and W. J. Conover "A comparison of three methods for selecting values of input variables in the analysis of output from a computer code," Technometrics Vol. 21, pp.239-245, 1971.

[218]I. M. Sobol, and S. Kucherenko "Derivative based global sensitivity measurers and their link with global sensitivity indices," Mathematics and Computers in Simulation, Vol. 79, No. 10, pp. 3009-3017.

[219]F. Pianosi, T. Wagener, "A simple and efficient method for global sensitivity analysis based on cumulative distribution functions," Environmental Modelling \& Software, Vol. 67, pp. 1-11, 2015.

[220]E. Borgonovo, W. Castaings, and S. Tarantola, "Model emulation and moment-independent sensitivity analysis: an application to environmental modelling," Environmental Modelling \& Software, Vol. 34. pp.105-115, 2012.
[221]S. D. Veiga "Global sensitivity analysis with dependence measures," Journal of Statistical Computation and Simulation, Vol. 85(7), pp.1283-1305, 2015.

[222]S. Razavi, R. Sheikholeslami, H. V. Gupta, and A. Haghnegahdar "VARS-Tool: a toolbox for comprehensive efficient and robust sensitivity and uncertainty analysis," Environmental Modelling \& Software, Vol. 112, pp. 95-107, 2019.

[223]J. M. Andre, S. Lacour, M. Hugot, Z. Olah, R. Joumard "Impact of the gearshift strategy on emission measurements", Artemis 3142 report, Report $\mathrm{n}^{\circ}$ LTE 0307 March 2003.

[224] M. H. Mohammadi and D. A. Lowther, "A Computational Study of Efficiency Map Calculation for Synchronous AC Motor Drives Including

Cross-Coupling and Saturation Effects," IEEE Trans. On Magnetics, Vol. 53, No.6, pp. 1-4, 2017.

[225]Q. Ma, A. El-Refaie, and B. Lequesne, "Low-Cost Interior Permanent Magnet Machine With Multiple Magnet Types," IEEE Trans. On Industry Application, Vol. 56, No. 2, pp. 1452-1463, 2020.

[226]K. Kiyota, and A. Chiba, "Design of Switched Reluctance Motor Competitive to 60-kW IPMSM in Third-Generation Hybrid Electric Vehicle," IEEE Trans. On Industry Application, Vol. 48, No. 6, pp. 2303-2309, 2012.

[227]K. Kiyota, T. Kakishima, and A. Chiba, "Comparison of Test Result and Design Stage Prediction of Switched Reluctance Motor Competitive With 60-kW Rare-Earth PM Motor," IEEE Trans. On Industry Electronics, Vol. 61, No. 10, pp. 5712-5721, 2014.

[228]T. Arakawa, M. Takemoto, S. Ogasawara, K. Inoue, O. Ozaki, H. Hojo, and H. Mitani, "Examination of an Interior Permanent Magnet Type Axial Gap Motor for the Hybrid Electric Vehicle," IEEE Trans. On Magnetics, Vol. 47, No. 10, pp. 3602-3605, 2011.

[229]D. G. Dorrell, A. M. Knight, L. Evans, and M. Popescu,, "Analysis and Design Techniques Applied to Hybrid Vehicle Drive MachinesAssessment of Alternative IPM and Induction Motor Topologies,' IEEE Trans. On Industrial Electronics, Vol. 59, No. 10, pp. 3690$3699,2012$. 